\title{
Individualized Immunological Data for Precise Classification of OCD Patients
}

\author{
Hugues Lamothe ${ }^{1,2,3}$, Jean-Marc Baleyte ${ }^{1,3}$, Pauline Smith ${ }^{2}$, Antoine Pelissolo ${ }^{3,4,5}$ \\ and Luc Mallet 2,3,4,6,* \\ 1 Centre Hospitalier Intercommunal de Créteil, 94000 Créteil, France; lamothehugues@gmail.com (H.L.); \\ jean-marc.baleyte@chicreteil.fr (J.-M.B.) \\ 2 Institut du Cerveau et de la Moelle Epinière, Sorbonne Universités, UPMC Univ Paris 06, CNRS, INSERM, \\ 75013 Paris, France; pauline.hh.smith@gmail.com \\ 3 Fondation FondaMental, 94000 Créteil, France; a.pelissolo@gmail.com \\ 4 Assistance Publique-Hôpitaux de Paris, Pôle de Psychiatrie, Hôpitaux Universitaires Henri \\ Mondor-Albert Chenevier, Université Paris-Est Créteil, 94000 Créteil, France \\ 5 INSERM, U955, Team 15, 94000 Créteil, France \\ 6 Department of Mental Health and Psychiatry, Global Health Institute, University of Geneva, \\ 1202 Geneva, Switzerland \\ * Correspondence: luc.mallet@inserm.fr; Tel.: +33-157-274-393
}

Received: 16 May 2018; Accepted: 3 August 2018; Published: 9 August 2018

\begin{abstract}
Obsessive-compulsive disorder (OCD) affects about 2\% of the general population, for which several etiological factors were identified. Important among these is immunological dysfunction. This review aims to show how immunology can inform specific etiological factors, and how distinguishing between these etiologies is important from a personalized treatment perspective. We found discrepancies concerning cytokines, raising the hypothesis of specific immunological etiological factors. Antibody studies support the existence of a potential autoimmune etiological factor. Infections may also provoke OCD symptoms, and therefore, could be considered as specific etiological factors with specific immunological impairments. Finally, we underline the importance of distinguishing between different etiological factors since some specific treatments already exist in the context of immunological factors for the improvement of classic treatments.
\end{abstract}

Keywords: psychiatry; OCD; obsessive-compulsive disorder; Tourette syndrome; immunology; cytokines; pediatric autoimmune neuropsychological disorders associated with streptococcal infection (PANDAS); pediatric acute-onset neuropsychiatric syndrome (PANS); Toxoplasma gondii; Streptococcus pyogenes

\section{Introduction}

Obsessive-compulsive disorder (OCD) is a major disabling disorder affecting about $2 \%$ of the population, and it incurs significant mental health costs [1]. The Diagnostic and Statistical Manual of Mental Disorders, Fifth Edition (DSM-5) defines OCD as comprising two major symptoms: obsessions (i.e., intrusive thoughts or mental images) and compulsions (i.e., repetitive movements or mental acts produced by the patient in response to obsessional thoughts, in order to decrease anxiety) [2].

Several hypotheses exist regarding the physiological basis of OCD with dysfunction of brain circuits involving the limbic cortex and basal ganglia being at the core of the disorder [1,3]. Indeed, several imaging studies found hyperactivity of the orbito-frontal cortex and anterior cingulate cortex [4], and effective treatments for severe forms of OCD act directly on these circuits [5,6]. Some authors proposed hypotheses involving dysfunction of microcircuits within these limbic loops [7]. However, 
hypotheses constructed to explain the underlying pathology of the disorders make no reference as to the origin of the dysfunctions.

An underlying genetic process could play an important role in the etiology of dysfunctional circuitry. Several genes were found through genomic association studies $[1,8]$. Among the genes implicated in OCD, dopamine-, glutamate-, or serotonin-related genes are the most studied [1,3], although they are not the only ones to be involved in OCD. A recent study aimed to identify rare de novo mutations based on exomes from 20 OCD parent-child trios patients [9]. Protein mutations were found in developmental and immunological pathways, such as transforming growth factor beta (TGF $\beta$ ) or complements. These results differ from the usual neurotransmitter gene mutations [9], and they provide arguments for immunological factors in OCD etiology. Furthermore, another study found a significant enrichment of the human leukocyte antigen/antigen D-related 4 (HLA-DR4) serotype allele in OCD patients [10]. According to the results of these genetic studies, abnormalities in immunological mechanisms could lead to OCD, and some specific mechanisms such as microglial dysfunction [11] or autoimmune processes [12] were hypothesized. Furthermore, not only can genes disrupt the immune system through mutations, but the environment can also influence it, through infections for example, subsequently leading to OCD, even with no genetic predisposition [13]. This question of a possible infectious etiology was also suspected in other psychiatric disorders [14].

As many as $25-40 \%$ of OCD patients are resistant to classical therapies, such as serotonin recapture inhibitors and cognitive behavioral therapy, and remain so despite advances in OCD treatment such as deep brain stimulation [15-17]. Any progress toward a better understanding of the biological basis could provide some solutions for resistant OCD patients. Hence, if a specific cluster of OCD patients with immunological dysfunctions could be determined, some specific treatment could emerge for them and resolve the enduring resistance problem for a minority of patients [18]. The aim of this review was, thus, to summarize the existing immunological data in OCD to show a possible immunological etiological factor in OCD that could be distinct from other factors (e.g., purely genetic OCD), and then, to raise the possibility of a more personalized and effective treatment.

\section{Method}

Our review used the PubMed database. We selected clinical human papers (English language) relevant to the human immunological field concerning OCD. The relevance of an article was based on the abstract published in PubMed. We did not restrain the period of search and reviewed all PubMed results.

Our exclusion criteria were as follows: case report format, small descriptive case series format, commentary format, review format, animal experiments, neurocognitive studies, control group with other psychiatric conditions, absence of OCD data (for example, studies looking for pediatric autoimmune neuropsychological disorders associated with streptococcal infection (PANDAS) etiology only in Tourette's patients were excluded). Furthermore, therapeutic trials were not selected when these were not targeted by the search terms. For example, when looking for cytokine impairment in OCD through "cytokines AND (OCD OR "obsessive compulsive disorder")" search terms, some therapeutic trials found were not selected.

When the same paper was found with different search terms, we specify this fact in the tables below. For example, when an article was found with both "cytokines AND (OCD OR "obsessive compulsive disorder")" and "antibody AND (OCD OR "obsessive compulsive disorder")" search terms, we detailed the article only in the first table section (here, the "cytokines AND (OCD OR "obsessive compulsive disorder")" table section); in the second table section (here, the "antibody AND (OCD OR "obsessive compulsive disorder")" table section), we only mentioned the article and directed the reader to the first table section for details.

The following terms were reviewed:

cytokines AND (OCD OR "obsessive-compulsive disorder") (67 papers, 22 included); antibody AND (OCD OR “obsessive-compulsive disorder") (163 papers, 33 included); anti-brain antibody 
and (OCD OR "obsessive-compulsive disorder") (6 papers, 3 included); ABGA AND (OCD OR "obsessive-compulsive disorder") (7 papers, 2 included); "white blood cells" AND (OCD OR "obsessive-compulsive disorder") (1 paper, 1 included); lymphocyte AND ("obsessive-compulsive disorder" OR OCD) (40 papers, 15 included); monocytes AND ("obsessive-compulsive disorder" OR OCD) (6 papers, 4 included); “NK cells" AND ("obsessive-compulsive disorder" OR OCD) (3 papers, 2 included); infection AND (OCD OR "obsessive-compulsive disorder") (243 papers, 9 included); Lyme AND (OCD OR "obsessive-compulsive disorder") (5 papers, 1 included); streptococcus AND (OCD OR "obsessive-compulsive disorder") (137 papers, 22 included); toxoplasma (OCD OR "obsessive-compulsive disorder") (8 papers, 4 included); (PANDAS OR PANS) AND treatment AND (OCD OR "obsessive-compulsive disorder" OR tic OR Tourette) (111 papers, 21 included); NSAID and (OCD OR "obsessive-compulsive disorder") (14 articles, 4 included); "anti-inflammatory" and (OCD OR "obsessive-compulsive disorder") (21 papers, 5 included); minocycline and (OCD OR "obsessive-compulsive disorder") (6 papers, 2 included); $\mathrm{N}$-acetylcysteine and (OCD OR "obsessive-compulsive disorder") (27 papers, 5 included).

The aim of the article was to describe and discuss the potential role of immunological factors in OCD etiology. Hence, even if the method was a systematic one, we wrote our article as a qualitative review to make it easier to read and understand. However, the articles cited in the text are referenced in the tables below, and, when contradictions occurred between articles, this is mentioned and reviewed qualitatively in the text.

\section{Immunological Changes in OCD}

\subsection{Cytokines}

Cytokines are molecules that allow communication between immune cells, or between immune cells and non-immune cells [19]. Studying cytokines can help us understand the mechanism and pathways of potential immunological disruption in OCD. The first studies on cytokine variations in OCD patients included very few patients and were negative except for a positive and significant correlation between IL-6 (interleukin-6) or soluble IL-6 receptor plasma levels and severity of compulsive behaviors [20,21] (Table 1). Further studies [22-30] were carried out enabling a meta-analysis [31] (Table 1), which found decreased IL-1 $\beta$ levels and decreased TNF $\alpha$ (tumor necrosis factor $\alpha$ ) levels in non-depressed OCD patients (but not in OCD patients with possible comorbid depression), and increased IL-6 levels in adult medication-free OCD patients (but not in OCD children with possible medication use) compared to controls. More recently, discrepancies were found with this previous meta-analysis concerning TNF- $\alpha$ with increased levels in OCD patients [32-34] (Table 1). Despite these discrepancies, the increased IL-6 levels seem a consistent result as they were replicated in a recent study $[34,35]$ (Table 1$)$.

Table 1. Cytokine studies.

\begin{tabular}{|c|c|c|c|}
\hline \multicolumn{4}{|c|}{ Cytokines AND (OCD OR “Obsessive Compulsive Disorder”) } \\
\hline Authors, Date & Subjects & Main Results & Significance \\
\hline $\begin{array}{l}\text { Jiang C. et al. (2018) } \\
\text { [36] Meta-analysis }\end{array}$ & $\begin{array}{l}435 \text { cases } 1073 \\
\text { controls }\end{array}$ & $\begin{array}{l}\text { TNF- } \alpha \text { polymorphisms } \\
\text {-> G vs. A model: OR }=1.01 ; 95 \% \text { CIs }=0.37-2.77 ; \\
\text { - } \text { GG vs. AA + AG model: OR =0.93; } 95 \% \text { CIs }=0.37-2.37 ; \\
\text {-> GG + AG vs. AA model: OR }=0.22 ; 95 \% \text { CIs }=0.06-0.73 ; \\
\text {-> GG vs. AA model: OR }=0.21 ; 95 \% \text { CIs }=0.06-0.71 ; \\
\text {-> AG + AA model: OR }=0.29 ; 95 \% \text { CIs }=0.07-1.16 ; \\
\text {-> GG + AA vs. AG model: OR }=1.17 ; 95 \% C I s=0.55-2.51\end{array}$ & $\begin{array}{l}p=0.981 \\
p=0.879 \\
p=0.014 \\
p=0.12 \\
p=0.081 \\
p=0.683\end{array}$ \\
\hline $\begin{array}{l}\text { Colak Sivri R. et al. } \\
\text { (2018) [32] }\end{array}$ & $\begin{array}{c}44 \text { OCD } \\
\text { patients } \\
40 \text { controls }\end{array}$ & $\begin{array}{l}->\text { OCD log-TNF- } \alpha>\text { controls log-TNF- } \alpha \\
->\text { OCD log-IL- } 12<\text { controls log-IL-12 } \\
\text { No difference concerning BDNF, TFG- } \beta \text { (tendency of increased level } \\
\text { in OCD patients), IL-1 } \beta \text { (tendency of decreased level in OCD } \\
\text { patients), IL-17, sTNFR1, sTNFR2, CCL3, CCL24 (tendency of } \\
\text { increased level in OCD patients), CCL8 }\end{array}$ & $\begin{array}{l}p<0.001 \\
p=0.014\end{array}$ \\
\hline
\end{tabular}


Table 1. Cont.

\begin{tabular}{|c|c|c|c|}
\hline \multicolumn{4}{|c|}{ Cytokines AND (OCD OR “Obsessive Compulsive Disorder”) } \\
\hline Authors, Date & Subjects & Main Results & Significance \\
\hline $\begin{array}{l}\text { Rodriguez N. et al. } \\
\text { (2017) [35] }\end{array}$ & $\begin{array}{l}102 \mathrm{OCD} \\
\text { patients } \\
47 \text { controls }\end{array}$ & $\begin{array}{l}\text {-> Monocytes percentage of OCD patients }>\text { controls } \\
\text {-> CD16+ monocytes percentage of OCD patients }>\text { controls } \\
\text { After LPS stimulation } \\
\text { - OCD-patients IL-1 } \beta>\text { controls IL-1 } \beta \\
\text { - OCD-patients IL- } 6>\text { controls IL-6 } \\
\text { - > OCD-patients GM-CSF }>\text { controls GM-CSF } \\
\text { - OCD-patients TNF- } \alpha>\text { controls TNF- } \alpha \\
\text { - OCD-patients IL- } 8>\text { controls IL- } 8\end{array}$ & $\begin{array}{l}p=0.005 \\
p=0.004 \\
p=0.049 \\
p=0.041 \\
p=0.013\end{array}$ \\
\hline $\begin{array}{l}\text { Simsek S. et al. } \\
\text { (2016) [33] }\end{array}$ & $\begin{array}{l}34 \mathrm{OCD} \\
\text { patients } \\
34 \text { controls }\end{array}$ & $\begin{array}{l}\text {-> OCD patients IL- } 17 \alpha>\text { controls IL-17 } \alpha \\
->\text { OCD patients TNF- } \alpha>\text { controls TNF- } \alpha \\
\text { - OCD patients IL- } 2>\text { controls IL-2 } \\
\text { No difference for IFN } \gamma, \text { IL-10, IL-6, IL-4 (tendency of increased level } \\
\text { in OCD patients) }\end{array}$ & $\begin{array}{l}p=0.03 \\
p=0.01 \\
p=0.02\end{array}$ \\
\hline $\begin{array}{l}\text { Rao NP. et al. (2015) } \\
\text { [34] }\end{array}$ & $\begin{array}{l}20 \mathrm{OCD} \\
\text { patients } \\
20 \text { controls }\end{array}$ & $\begin{array}{l}->\text { OCD patients IL- } 2>\text { controls IL-2 } \\
->\text { OCD patients IL- } 4>\text { controls IL- } 4 \\
->\text { OCD patients IL- } 6>\text { controls IL-6 } \\
->\text { OCD patients IL- } 10>\text { controls IL-10 } \\
->\text { OCD patients TNF- } \alpha>\text { controls TNF- } \alpha \\
\text { No difference concerning IFN- } \gamma\end{array}$ & $\begin{array}{l}p=0.005 \\
p=0.007 \\
p=0.002 \\
p=0.006 \\
p=0.005\end{array}$ \\
\hline $\begin{array}{l}\text { Uguz F. et al. (2014) } \\
\text { [37] }\end{array}$ & $\begin{array}{l}7 \text { OCD patients } \\
30 \text { controls }\end{array}$ & $\begin{array}{l}->\text { cord blood TNF- } \alpha \text { of new born infants of women with OCD }> \\
\text { cord blood TNF- } \alpha \text { of new born infants of control women }\end{array}$ & $p=0.036$ \\
\hline $\begin{array}{l}\text { Bo Y. et al. (2013) } \\
\quad[38]\end{array}$ & $\begin{array}{l}241 \mathrm{OCD} \\
\text { patients } \\
444 \text { controls }\end{array}$ & $\begin{array}{l}\text { IL-1 } \beta-511 C / T \text { polymorphism } \\
\text { No difference between OCD patients and controls }\end{array}$ & \\
\hline $\begin{array}{l}\text { Zhang X. et al. } \\
\text { (2012) [39] }\end{array}$ & $\begin{array}{l}200 \text { OCD } \\
\text { patients } \\
294 \text { controls }\end{array}$ & $\begin{array}{l}\text { MCP-1-2518G/A polymorphism } \\
\text { No difference between OCD patients and controls }\end{array}$ & \\
\hline $\begin{array}{l}\text { Liu S. et al. (2012) } \\
\text { [40] }\end{array}$ & $\begin{array}{l}187 \mathrm{OCD} \\
\text { patients } \\
281 \text { controls }\end{array}$ & $\begin{array}{l}\text { IL-8-251T/A polymorphism } \\
\text { No difference }\end{array}$ & \\
\hline $\begin{array}{l}\text { Gray SM. et al. } \\
(2012)[31] \\
\text { Meta-analysis }\end{array}$ & $\begin{array}{l}169 \text { OCD } \\
\text { patients } \\
215 \text { controls }\end{array}$ & $\begin{array}{l}\text {-> Decreased IL- } 1 \beta \text { in OCD patients } \\
->\text { Increased IL- } 6 \text { in adult free-medication OCD patients } \\
\text { No difference concerning IL- } 6 \text { in OCD children } \\
->\text { Decreased TNF- } \alpha \text { in OCD patients without depression } \\
\text { No difference in TNF- } \alpha \text { when depressed patients are considered }\end{array}$ & $\begin{array}{l}p<0.01 \\
p=0.02 \\
p<0.001\end{array}$ \\
\hline $\begin{array}{l}\text { Cappi C. et al. } \\
\text { (2012) [22] }\end{array}$ & $\begin{array}{l}183 \text { OCD } \\
\text { patients } \\
249 \text { controls }\end{array}$ & $\begin{array}{l}\text { TNF- } \alpha \text { A/G polymorphism } \\
->\text { Association of allele A with OCD }\left(\chi^{2}, \text { rs } 361525\right)\end{array}$ & $p=0.007$ \\
\hline $\begin{array}{l}\text { Fontenelle LF. et al. } \\
\text { (2012) [23] }\end{array}$ & $\begin{array}{l}40 \mathrm{OCD} \\
\text { patients } \\
40 \text { controls }\end{array}$ & $\begin{array}{l}\text {-> OCD patients CCL3 > controls CCL3 } \\
\text { - OCD patients CXCL8 > controls CXCL8 } \\
\text { - OCD patients sTNFR1 > controls sTNFR1 } \\
\text { - OCD patients sTNFR2 > controls sTNFR2 } \\
\text { No difference between OCD and controls concerning CCL2, CCL11, } \\
\text { CCL24 (tendency of increased level in OCD patients), CXCL9, } \\
\text { CXCL10 (tendency of decreased level in OCD patients), IL-1ra, } \\
\text { TNF- } \alpha .\end{array}$ & $\begin{array}{c}p=0.03 \\
p<0.001 \\
p<0.001 \\
p<0.01\end{array}$ \\
\hline $\begin{array}{l}\text { Fluitman SB et al. } \\
\text { (2010) [24] }\end{array}$ & $\begin{array}{l}10 \mathrm{OCD} \\
\text { patients } \\
10 \text { controls }\end{array}$ & $\begin{array}{l}\text { During disgust exposure: } \\
\text {-> LPS-stimulated TNF- } \alpha \text { in OCD patients decreased after disgust } \\
\text { exposure } \\
\text { LPS-stimulated TNF- } \alpha \text { in controls not changed after disgust } \\
\text { exposure } \\
\text {-> LPS-stimulated IL- } 6 \text { in OCD patients decreased after disgust } \\
\text { exposure } \\
\text { LPS-stimulated IL-6 in control not changed after disgust exposure }\end{array}$ & $p=0.040$ \\
\hline $\begin{array}{l}\text { Fluitman S. et al. } \\
\text { (2010) [25] }\end{array}$ & $\begin{array}{l}26 \mathrm{OCD} \\
\text { patients } \\
52 \text { controls }\end{array}$ & $\begin{array}{l}\text {-> OCD patients LPS-stimulated IL-6 < control LPS-stimulated IL-6 } \\
\text { No difference concerning LPS-stimulated IL-8 and TNF- } \alpha\end{array}$ & $p=0.016$ \\
\hline $\begin{array}{l}\text { Hounie AG et al. } \\
\quad(2008)[26]\end{array}$ & $\begin{array}{l}111 \text { OCD } \\
\text { patients } \\
250 \text { controls }\end{array}$ & $\begin{array}{l}\text { TNF- } \alpha-A / G \text { polymorphism } \\
->\text { Association of the A allele with OCD for } 238 \text { G/A and } 308 \text { G/A } \\
\left(\chi^{2}\right)\end{array}$ & $\begin{array}{l}p=0.0005 \text { and } \\
0.007 \\
\text { respectively }\end{array}$ \\
\hline
\end{tabular}


Table 1. Cont

\begin{tabular}{|c|c|c|c|}
\hline \multicolumn{4}{|c|}{ Cytokines AND (OCD OR “Obsessive Compulsive Disorder”) } \\
\hline Authors, Date & Subjects & Main Results & Significance \\
\hline \multirow{2}{*}{$\begin{array}{l}\text { Konuk N. et al. } \\
\text { (2007) [27] }\end{array}$} & \multirow{2}{*}{$\begin{array}{l}31 \mathrm{OCD} \\
\text { patients } \\
31 \text { controls }\end{array}$} & -> OCD patients TNF- $\alpha>$ control TNF- $\alpha$ & $p<0.001$ \\
\hline & & -> OCD patients IL- 6 > control IL- 6 & $p<0.001$ \\
\hline \multirow{4}{*}{$\begin{array}{l}\text { Denys D. et al. } \\
\text { (2004) [28] }\end{array}$} & \multirow{4}{*}{$\begin{array}{c}50 \text { OCD } \\
\text { patients } \\
25 \text { controls }\end{array}$} & -> OCD patients LPS stimulated IL-6 > control LPS stimulated IL-6 & $p=0.004$ \\
\hline & & & $p<0.001$ \\
\hline & & $\rightarrow$ decreased NK cells activity in OCD patients & \multirow[t]{2}{*}{$p=0.002$} \\
\hline & & No difference concerning LPS-stimulated IL-10 & \\
\hline $\begin{array}{l}\text { Carpenter LL. et al. } \\
\text { (2002) [41] }\end{array}$ & $\begin{array}{c}26 \text { OCD } \\
\text { patients } \\
26 \text { controls }\end{array}$ & No difference concerning CSF IL-6 level. & \\
\hline \multirow{2}{*}{$\begin{array}{l}\text { Monteleone P. et al. } \\
\text { (1998) [29] }\end{array}$} & \multirow{2}{*}{$\begin{array}{c}14 \text { OCD } \\
\text { patients } \\
14 \text { controls }\end{array}$} & -> OCD patients TNF- $\alpha<$ control TNF- $\alpha$ & \multirow[t]{2}{*}{$p=0.001$} \\
\hline & & No difference concerning IL- 6 and IL-1 $\beta$ & \\
\hline \multirow{2}{*}{$\begin{array}{l}\text { Brambilla F. et al. } \\
\text { (1997) [30] }\end{array}$} & \multirow{2}{*}{$\begin{array}{c}27 \mathrm{OCD} \\
\text { patients } \\
27 \text { controls }\end{array}$} & -> OCD patients IL- $1 \beta<$ control IL- $1 \beta$ & \multirow[t]{2}{*}{$p=0.0004$} \\
\hline & & $->$ OCD patients TNF- $\alpha<$ control TNF- $\alpha$ & \\
\hline $\begin{array}{l}\text { Weizman R. et al. } \\
\text { (1996) [20] }\end{array}$ & $\begin{array}{c}11 \text { OCD } \\
\text { patients } \\
11 \text { controls }\end{array}$ & $\begin{array}{l}\text { No difference concerning IL-1 } \beta \text {, IL-2, and IL-3-LA production } \\
\text { between OCD patients and controls }\end{array}$ & \\
\hline $\begin{array}{l}\text { Maes M. et al. } \\
\text { (1994) [21] }\end{array}$ & $\begin{array}{c}19 \text { OCD } \\
\text { patients } \\
19 \text { controls }\end{array}$ & No difference concerning IL-1 $\beta$, IL-6, sIL-2R, sIL-6R & \\
\hline
\end{tabular}

A/G: adenine/guanine; BDNF: brain-derived neurotrophic factor; C/T: cytosine/thymine; CCL: chemokine ligand; CIs = confidence interval; CSF: cerebrospinal fluid; CXCL: chemokine (C-X-C motif) ligand; G/A: guanine/adenine; GM-CSF: granulocyte-macrophage colony stimulating factor; IFN: interferon; IL: interleukin; IL-1ra: interleukin 1 receptor antagonist; LA: like activity; LPS = lipopolysaccharide; MCP: monocyte chemoattractant protein; NK: natural killer; OCD: obsessive-compulsive disorder; OR = odds ratio; sIL-2R: soluble interleukine-2 receptor; sTNFR: soluble tumor necrosis factor receptor; T/A: thymine/adenine; TNF: tumor necrosis factor.

The fact that IL-6 levels are higher in autoimmune diseases (e.g., rheumatoid arthritis) [19] raises the hypothesis that increased IL-6 levels in OCD could favor the existence of an autoimmune etiological factor. Furthermore, tocilizumab, an IL-6 receptor-neutralizing antibody, appears as a putative treatment in some cases of OCD as this molecule was always found effective in some autoimmune disorders where IL-6 is involved [19]. We could, thus, hypothesize that tocilizumab or other specific immunological treatments could help some specific OCD patients with a possible immunological etiological factor.

It is known also that both IL-6 and TNF $\alpha$ can be involved in asthma pathophysiology and allergic diseases [42], and allergic diseases would appear to be more frequent in OCD patients [43], giving weight to elevated IL- 6 and TNF $\alpha$ levels in some OCD cases.

$\mathrm{TNF} \alpha, \mathrm{IL}-1 \beta$, and IL-6 are inflammatory cytokines (for a very complete review, see Reference [42]). $\mathrm{TNF} \alpha$ is produced by a wide range of cells including T- or B-cells and monocytes (including microglia), and it targets all nucleated cells. TNF $\alpha$ has a complex role, being both pro-inflammatory and immunosuppressive. In the brain, TNF $\alpha$ could be involved in synapses scaling with high levels of TNF $\alpha$ favoring LTP (long term potentiation) and low levels of TNF $\alpha$ favoring LTD (long term depression) $[44,45]$. Progranulin mutations were found to be associated with hyperexcitability of nucleus accumbens spiny neurons in mice, in line with hyperactivity of cortico-striatal loops in OCD [1], and elevated TNF $\alpha$ levels and hyperactivation of microglia [46]. With the progranulin gene restored, OCD-like behavior disappeared in mice [46]. Frontoparietal dementia patients showing mutations of progranulin presented OCD [46].

IL-1 $\beta$ is also produced by microglia and targets T-cells or endothelial and epithelial cells [42].

IL-6 is produced by both astrocytes and microglia, and IL-6 exposure could increase synaptic activity (for an excellent review on IL-6 central nervous system (CNS) effects, see Reference [47]). 
In summary, the literature on cytokines involved in OCD is difficult to interpret as contradictory results are often found. These discrepancies could be due to the heterogeneity of patients studied, e.g., children vs. adults, and they emphasize the importance of considering the immunological status of recruited patients. Thus, differences in symptoms, and their development or response to treatment between OCD patients with and without modified IL- 6 and TNF $\alpha$ levels would suggest the possibility of a specific immunological OCD cluster.

\subsection{Antibodies}

Most studies concerning antibodies in OCD concern pediatric autoimmune neuropsychological disorders associated with streptococcal (PANDAS) infections.

Studies found that a subset of patients suffering from OCD showed high levels of anti-basal ganglia antibodies (ABGAs) and anti-streptolysin O antibodies (ASO) in the blood or corticospinal fluid (CSF) [48-51] (Table 2). These studies strongly support the existence of an autoimmune etiological factor in OCD. However, discrepancies still exist: ABGAs were found in OCD patients (and not in controls), but not in all OCD patients [49] (Table 2).

Table 2. Autoimmunity and OCD.

\begin{tabular}{|c|c|c|c|}
\hline \multicolumn{4}{|c|}{ Antibody AND (OCD OR “Obsessive Compulsive Disorder”) } \\
\hline Authors, Date & Subjects & Main Results & Significance \\
\hline $\begin{array}{l}\text { Akaltun I. et al. } \\
\text { (2018) [52] }\end{array}$ & $\begin{array}{l}60 \text { OCD } \\
60 \text { controls }\end{array}$ & $\begin{array}{l}\text {-> Toxoplasma IgG levels related to OCD status } \\
\text {-> IgG positivity individuals: increased risk of OCD: } \\
\text { OR }=4.84,95 \% \text { CIs }=1.78-13.12\end{array}$ & $\begin{array}{l}p=0.001 \\
p=0.002\end{array}$ \\
\hline $\begin{array}{l}\text { Mataix-Cols D. et al. } \\
\text { (2017) [53] }\end{array}$ & $\begin{array}{c}30082 \text { OCD } \\
472874 \text { patients }\end{array}$ & $\begin{array}{l}\text {-> Augmentation of the risk to develop autoimmune } \\
\text { disease: } \mathrm{OR}=1.43 ; 95 \% \mathrm{CIs}=1.37-1.49\end{array}$ & $p<0.01$ \\
\hline $\begin{array}{c}\text { Flegr J. et al. (2017) } \\
\text { [54] }\end{array}$ & $\begin{array}{l}281 \text { men and } 831 \text { women } \\
\text { not infected } \\
65 \text { men and } 350 \text { women } \\
\text { infected with toxoplasma }\end{array}$ & $\begin{array}{l}->\text { Association between toxoplasma infection and OCD: } \\
\mathrm{OR}=2.27,95 \% \mathrm{CI}=1.01-5.09\end{array}$ & $p=0.047$ \\
\hline $\begin{array}{l}\text { Sutterland AL. et al. } \\
\text { (2015) [14] } \\
\text { Meta-analysis }\end{array}$ & $\begin{array}{l}\text { No information but } 2 \\
\text { studies included }\end{array}$ & $\begin{array}{l}->\text { Association between OCD status and toxoplasma } \\
\text { infection: } \mathrm{OR}=3.4 ; 95 \% \mathrm{CIs}=1.73-6.68\end{array}$ & $p=0.0004$ \\
\hline $\begin{array}{l}\text { Nicolini H. et al. } \\
\text { (2015) [55] }\end{array}$ & $\begin{array}{l}37 \text { PANDAS/OCD or tics } \\
\text { patients } \\
12 \text { controls }\end{array}$ & $\begin{array}{l}->\text { OCD patients anti-enolase }>\text { controls anti-enolase } \\
->\text { OCD patients anti-streptococcal proteins }>\text { controls } \\
\text { anti-streptococcal proteins } \\
\text { No differences concerning anti-neural antibodies. }\end{array}$ & $\begin{array}{l}p=0.035 \\
p=0.05\end{array}$ \\
\hline $\begin{array}{l}\text { Singer HS. et al. } \\
\text { (2015) [56] }\end{array}$ & $\begin{array}{l}8 \text { PANDAS/OCD or tics } \\
\text { patients } \\
70 \text { controls }\end{array}$ & $\begin{array}{l}\text { No association between clinical exacerbation and } \\
\text { anti-tubulin, anti-lysoganglioside GM1, anti D1R, anti D2R } \\
\text { titer. }\end{array}$ & \\
\hline $\begin{array}{l}\text { Frankovich J. et al. } \\
\quad \text { (2015) [57] }\end{array}$ & $\begin{array}{l}19 \text { PANS/OCD or eating } \\
\text { disorder patients } \\
28 \text { non-PANS but OCD or } \\
\text { eating disorder patients }\end{array}$ & $\begin{array}{l}\text { No difference concerning comorbidities (anxiety, mood } \\
\text { disorder, irritability, suicidality) } \\
\text { No difference concerning Ig levels } \\
\text { No difference concerning remitting course, chronic course. }\end{array}$ & \\
\hline $\begin{array}{l}\text { Cox CJ. et al. (2015) } \\
{[58]}\end{array}$ & $\begin{array}{l}311 \text { PANDAS/OCD or tics } \\
\text { patients } \\
16 \text { controls }\end{array}$ & $\begin{array}{l}\text {-> PANDAS patients anti-D1R patients }>\text { controls anti-D1R } \\
\text {-> PANDAS patients anti-lysoganglioside }>\text { controls } \\
\text { anti-lysoganglioside }\end{array}$ & $\begin{array}{l}p<0.0001 \\
p=0.0001\end{array}$ \\
\hline $\begin{array}{l}\text { Ebrahimi Taj F. et al. } \\
\text { (2015) [59] }\end{array}$ & $\begin{array}{l}76 \text { OCD/ADHD patients } \\
39 \text { controls }\end{array}$ & $\begin{array}{l}\text {-> OCD/ADHD patients anti-streptolysin } \mathrm{O}>\text { controls } \\
\text { anti-streptolysin O } \\
\text {-> OCD/ADHD patients anti-streptokinase }>\text { controls } \\
\text { anti-streptokinase } \\
\text {-> OCD/ADHD patients anti-DNase B > controls } \\
\text { anti-DNase B }\end{array}$ & $\begin{array}{l}p<0.0001 \\
p<0.0001 \\
p<0.0001\end{array}$ \\
\hline $\begin{array}{l}\text { Murphy TK. et al. } \\
\text { (2015) [60] }\end{array}$ & 43 PANS/OCD patients & $\begin{array}{l}\text { infectious triggers: } 58 \% \text { of GAS, } 12 \% \text { of mycoplasma } \\
\text { pneumoniae, } 37 \text { of upper respiratory infection, } 2 \% \text { of Lyme } \\
\text { No differences between patients with tics and without tics } \\
\text { concerning anti-DNase B, ASO, Mycoplasma IgM/IgG, } \\
\text { Lyme screen, age of onset, CY-BOCS score, Y-GTSS score }\end{array}$ & \\
\hline
\end{tabular}


Table 2. Cont.

\begin{tabular}{|c|c|c|c|}
\hline \multicolumn{4}{|c|}{ Antibody AND (OCD OR “Obsessive Compulsive Disorder”) } \\
\hline Authors, Date & Subjects & Main Results & Significance \\
\hline $\begin{array}{l}\text { Murphy TK. et al. } \\
\quad \text { (2012) [61] }\end{array}$ & $\begin{array}{l}41 \text { PANDAS/OCD or tic } \\
\text { patients } \\
68 \text { non-PANDAS but OCD } \\
\text { or tic patients }\end{array}$ & $\begin{array}{l}->\text { PANDAS patients remissions }>\text { non-PANDAS patients } \\
\text { remissions } \\
->\text { PANDAS patients dramatic onset }>\text { non-PANDAS } \\
\text { patients dramatic onset } \\
\text {-> PANDAS patients ASO/anti-DNase }>\text { non-PANDAS } \\
\text { patients ASO/anti-DNaseB } \\
->\text { remission in PANDAS patients after antibiotic treatment } \\
>\text { remission in non-PANDAS after antibiotic treatment }\end{array}$ & $\begin{array}{l}p<0.05 \\
p<0.05 \\
p<0.0001 \\
p<0.01\end{array}$ \\
\hline $\begin{array}{l}\text { Leckman JF et al. } \\
\quad \text { (2011) [62] }\end{array}$ & $\begin{array}{l}31 \text { PANDAS/OCD or tic } \\
\text { patients } \\
53 \text { non-PANDAS/OCD or } \\
\text { tic patients }\end{array}$ & $\begin{array}{l}\text { No association between clinical exacerbation and new } \\
\text { GAS infection. }\end{array}$ & \\
\hline $\begin{array}{l}\text { Miman O. et al. } \\
\quad(2010)[63]\end{array}$ & $\begin{array}{l}42 \text { OCD patients } \\
100 \text { controls }\end{array}$ & $\begin{array}{l}->\text { OCD patients anti-toxoplasma IgG > controls } \\
\text { anti-toxoplasma IgG }\end{array}$ & $p<0.01$ \\
\hline $\begin{array}{l}\text { Bhattacharyya S. et al. } \\
\text { (2009) [48] }\end{array}$ & $\begin{array}{l}23 \text { OCD patients } \\
23 \text { controls }\end{array}$ & $\begin{array}{l}->\text { more CSF anti-brain antibody binding to basal ganglia } \\
\text { and thalamus for OCD patients than for patients } \\
\text {-> More CSF glutamate and glycine in OCD patients than } \\
\text { in controls }\end{array}$ & $\begin{array}{l}p<0.05 \\
p<0.001\end{array}$ \\
\hline $\begin{array}{l}\text { Gause C. et al. (2009) } \\
\text { [64] }\end{array}$ & $\begin{array}{l}13 \text { OCD only patients } \\
20 \text { PANDAS/OCD } \\
\text { patients } \\
23 \text { PANDAS/tic patients } \\
29 \text { controls }\end{array}$ & $\begin{array}{l}\text { No difference concerning ASO titers } \\
\text { No difference concerning serum IgG } \\
\text {-> More anti-neural antibodies PANDAS/OCD than in } \\
\text { other groups }\end{array}$ & $p<0.009$ \\
\hline $\begin{array}{l}\text { Morer A. et al. (2008) } \\
\text { [49] }\end{array}$ & $\begin{array}{l}32 \text { OCD patients } \\
19 \text { controls }\end{array}$ & $\begin{array}{l}\text { No anti-basal ganglia antibody detected by } \\
\text { immunohistochemistry } \\
\text {-> Anti-basal ganglia antibodies in OCD patients and no in } \\
\text { control detected by immunoscreening } \\
\text { No difference concerning ASO titers }\end{array}$ & \\
\hline \multirow{2}{*}{$\begin{array}{l}\text { Kirvan CA. et al. } \\
\text { (2006) [65] }\end{array}$} & $\begin{array}{l}16 \text { PANDAS/OCD or tic } \\
\text { patients } \\
25 \text { non- }\end{array}$ & $\begin{array}{l}->\text { lysoganglioside GM1 concentration required to inhibit } \\
\text { binding PANDAS sera to GlcNAc (an epitope of GAS } \\
\text { carbohydrate) < lysoganglioside GM1 concentration } \\
\text { required to inhibit binding non-PANDAS sera to GlcNAc } \\
\text { (an epitope of GAS carbohydrate) }\end{array}$ & $p<0.05$ \\
\hline & $\begin{array}{l}\text { PANDAS/OCD or tic or } \\
\text { ADHD patients }\end{array}$ & $\begin{array}{l}\text {-> lysoganglioside GM1 = specific inhibitor of PANDAS } \\
\text { IgG binding to GlcNAc } \\
->\text { PANDAS sera induced activation of CaM kinase II more } \\
\text { than non-PANDAS sera => PANDAS serum responsible } \\
\text { for cell signaling }\end{array}$ & $p=0.001$ \\
\hline $\begin{array}{l}\text { Morer A. et al. (2006) } \\
{[66]}\end{array}$ & $\begin{array}{l}18 \text { early onset OCD } \\
21 \text { late onset } \mathrm{OCD}\end{array}$ & $\begin{array}{l}->\text { Child OCD ASO titer > adult OCD ASO titer } \\
\text { No difference for D8/D17 }\end{array}$ & $p=0.031$ \\
\hline $\begin{array}{l}\text { Singer HS. et al. } \\
\text { (2005) [67] }\end{array}$ & $\begin{array}{l}48 \text { PANDAS (OCD or tic } \\
\text { status not informed) } \\
\text { patients } \\
43 \text { controls }\end{array}$ & $\begin{array}{l}\text { No median ELISA optical density difference concerning } \\
\text { serum antibodies } \\
\text { No difference concerning reactivity against pyruvate } \\
\text { kinase M1, } \alpha \text {-enolase, } \gamma \text {-enolase, aldolase C }\end{array}$ & \\
\hline $\begin{array}{l}\text { Pavone P. et al. (2004) } \\
\text { [68] }\end{array}$ & $\begin{array}{l}22 \text { PANDAS (OCD or tic } \\
\text { status no informed) } \\
\text { patients } \\
22 \text { GAS uncomplicated } \\
\text { infected patients }\end{array}$ & $\begin{array}{l}\text {-> PANDAS anti-basal ganglia antibody > GAS patients } \\
\text { anti-basal ganglia antibody } \\
\text { No difference concerning ASO or anti DNase B antibody }\end{array}$ & $p<0.001$ \\
\hline $\begin{array}{l}\text { Murphy TK. et al. } \\
\text { (2004) [69] }\end{array}$ & $\begin{array}{l}15 \text { OCD or tics patients } \\
\text { with large symptom } \\
\text { fluctuations } \\
10 \text { OCD or tics patients } \\
\text { without large symptom } \\
\text { fluctuations }\end{array}$ & $\begin{array}{l}->\text { positive correlation between OCD severity and ASO } \\
\text { titer in patients with large symptom fluctuations }\end{array}$ & $p=0.0130$ \\
\hline $\begin{array}{l}\text { Luo F. et al. (2004) } \\
\text { [70] }\end{array}$ & $\begin{array}{l}47 \text { OCD or tic patients } \\
19 \text { controls }\end{array}$ & $\begin{array}{l}\text {-> OCD or tic patients percentages of D8/D17 positive } \\
\text { cells }>\text { controls percentages of D8/D17 positive cells }\end{array}$ & $p=0.0029$ \\
\hline $\begin{array}{l}\text { Inoff-Germain } \\
\text { G. et al. (2003) [71] }\end{array}$ & $\begin{array}{l}108 \text { positive children for } \\
\text { D8/17 marker } \\
132 \text { negative dor D8/17 } \\
\text { marker }\end{array}$ & $\begin{array}{l}\text { No association between D8/17 marker status and OCD or } \\
\text { tic status }\end{array}$ & \\
\hline
\end{tabular}


Table 2. Cont.

\begin{tabular}{|c|c|c|c|}
\hline \multicolumn{4}{|c|}{ Antibody AND (OCD OR “Obsessive Compulsive Disorder”) } \\
\hline Authors, Date & Subjects & Main Results & Significance \\
\hline $\begin{array}{l}\text { Murphy ML. et al. } \\
\text { (2002) [72] }\end{array}$ & 12 PANDAS OCD patients & $\begin{array}{l}\text {-> abrupt appearance of OCD symptoms } \\
\text {-> elevated anti-DNase B titer } \\
->\text { mean age at onset }=7 \text { years }\end{array}$ & \\
\hline $\begin{array}{l}\text { Eisen JL. et al. (2001) } \\
\text { [73] }\end{array}$ & $\begin{array}{l}29 \text { OCD patients } \\
26 \text { controls }\end{array}$ & No difference in D8/D17 marker positivity & \\
\hline $\begin{array}{l}\text { Murphy TK. et al. } \\
\text { (2001) [74] }\end{array}$ & $\begin{array}{l}32 \text { OCD or tic patients } \\
12 \text { controls }\end{array}$ & -> OCD/tic patients D8/D17 titers > control D8/17 titers & $p=0.01$ \\
\hline $\begin{array}{l}\text { Peterson BS. et al. } \\
\quad \text { (2000) [75] }\end{array}$ & $\begin{array}{l}105 \text { tic, OCD or ADHD } \\
\text { patients } \\
37 \text { controls }\end{array}$ & $\begin{array}{l}\text { No association between OCD or tic disorder and ASO or } \\
\text { anti-DNase B titers } \\
->\text { ASO or anti-DNase B titers positively correlated with } \\
\text { putamen or globus pallidus volume in OCD patients }\end{array}$ & $\begin{array}{l}\text { No access to } \\
\text { p-values }\end{array}$ \\
\hline $\begin{array}{l}\text { Marazziti D. et al. } \\
\quad(1999) \text { [76] }\end{array}$ & $\begin{array}{l}20 \text { OCD patients } \\
20 \text { controls }\end{array}$ & $\begin{array}{l}->\text { Increased CD8+ lymphocytes in OCD patients } \\
->\text { decreased CD4+ lymphocytes in OCD patients }\end{array}$ & $\begin{array}{l}p=0.002 \\
p=0.003\end{array}$ \\
\hline $\begin{array}{l}\text { Chapman F. et al. } \\
\text { (1998) [77] }\end{array}$ & $\begin{array}{l}41 \text { OCD or tic patients } \\
31 \text { controls }\end{array}$ & $\begin{array}{l}\text {-> OCD or tic patients D8/D17 positivity > control } \\
\text { D8/D17 positivity }\end{array}$ & $P<0.0001$ \\
\hline $\begin{array}{l}\text { Khanna S. et al. } \\
\text { (1997) [78] }\end{array}$ & $\begin{array}{l}76 \text { OCD patients } \\
55 \text { controls }\end{array}$ & $\begin{array}{l}\text {-> OCD patients mumps and HSV-I IgG > control mumps } \\
\text { and HSV-I IgG }\end{array}$ & $p<0.05$ \\
\hline $\begin{array}{l}\text { Khanna S. et al. } \\
\text { (1997) [79] }\end{array}$ & $\begin{array}{l}76 \text { OCD patients } \\
30 \text { controls }\end{array}$ & $\begin{array}{l}\text {-> OCD patients measles CSF IgG }<\text { control measles CSF } \\
\text { IgG } \\
->\text { OCD patient herpes CSF IgG }>\text { control herpes CSF IgG }\end{array}$ & $\begin{array}{l}p<0.001 \\
p<0.05\end{array}$ \\
\hline $\begin{array}{l}\text { Murphy TK. et al. } \\
\quad(1997)[80]\end{array}$ & $\begin{array}{l}31 \text { OCD or tic patients } \\
21 \text { controls }\end{array}$ & $\begin{array}{l}\text {-> OCD patients D8/17 positivity > control D8/17 } \\
\text { positivity } \\
\text { No difference concerning ASO, anti-DNase B and } \\
\text { anti-neural antibodies }\end{array}$ & $p<0.001$ \\
\hline $\begin{array}{l}\text { Swedo SE. et al. } \\
\text { (1997) [81] }\end{array}$ & $\begin{array}{l}27 \text { PANDAS/OCD or tic } \\
\text { patients } \\
24 \text { controls }\end{array}$ & $\begin{array}{l}\text {-> PANDAS/OCD or tic patients D8/D17 positivity > } \\
\text { control D8/D17 positivity }\end{array}$ & $p<0.0001$ \\
\hline \multicolumn{4}{|c|}{ Anti-brain antibody and (OCD OR "obsessive-compulsive disorder") } \\
\hline $\begin{array}{l}\text { Bhattacharyya S. et al. } \\
\text { (2009) [48] }\end{array}$ & \multicolumn{3}{|c|}{ Cf. antibody AND (OCD OR “obsessive compulsive disorder”) } \\
\hline $\begin{array}{l}\text { Dale RC. et al. (2005) } \\
\text { [50] }\end{array}$ & $\begin{array}{l}50 \text { OCD patients } \\
40 \text { controls with } \\
\text { uncomplicated } \\
\text { streptococcal infection }\end{array}$ & $->$ ABGA level in OCD patients > ABGA level in controls & $p<0.005$ \\
\hline $\begin{array}{l}\text { Pavone P. et al. (2004) } \\
\text { [68] }\end{array}$ & \multicolumn{3}{|c|}{ Cf. antibody AND (OCD OR “obsessive compulsive disorder") } \\
\hline \multicolumn{4}{|c|}{ ABGA and (OCD OR “obsessive-compulsive disorder”) } \\
\hline $\begin{array}{l}\text { Pearlman DM. et al. } \\
\text { (2014) [51] } \\
\text { Meta-analysis }\end{array}$ & $\begin{array}{l}297 \text { OCD patients } \\
406 \text { controls }\end{array}$ & $\begin{array}{l}\text {-> ABGA seropositivity in OCD patients > ABGA } \\
\text { seropositivity in controls }\end{array}$ & $p<0.0001$ \\
\hline $\begin{array}{l}\text { Dale RC. et al. (2005) } \\
\text { [50] }\end{array}$ & \multicolumn{3}{|c|}{ Cf. Anti-brain antibody and (OCD OR "obsessive-compulsive disorder") } \\
\hline $\begin{array}{l}\text { ABGA }=\text { anti-basa } \\
\text { CaM Kinase II = } \\
\text { intervals; CSF = ce } \\
1 \text { receptor;D2R }= \\
\text { GAS = group A } \\
=\text { immunoglobuli } \\
\text { neuropsychologic } \\
\text { syndrome; Y-GTS }\end{array}$ & $\begin{array}{l}\text { ganglia antibody; ADHD } \\
\text { Ca }{ }^{2+} / \text { calmodulin dependen } \\
\text { rebrospinal fluid; CY-BOCS } \\
\text { = dopamine } 2 \text { receptor; D_ } \\
\text { streptococcus; GM1 = mor } \\
\text { in; OCD: obsessive-compul } \\
\text { al disorders associated with } \\
\mathrm{S}=\text { Yale global tic severity s }\end{array}$ & $\begin{array}{l}\text { =attention deficit/hyperactivity disorder; } \mathrm{ASO}=\text { anti-strep } \\
\text { t protein kinase II; } \mathrm{CD}=\text { cluster of differentiation; } \mathrm{CIs}=\mathrm{c} \\
=\text { children's Yale-Brown obsessive-compulsive scale; } \mathrm{D} 1 \mathrm{R}= \\
\text { and } \mathrm{D} 17=\mathrm{B} \text { lymphocyte antigen; DNase }=\text { deoxyrib } \\
\text { osialotetrahexosylganglioside } 1 \text {; HSV = herpes simplex } \\
\text { sive disorder; OR = odds ratio; PANDAS = pediatric aut } \\
\text { treptococcal infection; PANS = pediatric acute-onset neurop } \\
\text { cale. }\end{array}$ & $\begin{array}{l}\text { olysin } \mathrm{O} ; \\
\text { nfidence } \\
\text { lopamine } \\
\text { nuclease; } \\
\text { virus; Ig } \\
\text { immune } \\
\text { vchiatric }\end{array}$ \\
\hline
\end{tabular}

Furthermore, it was shown that patients suffering from rheumatic fever-a disorder linked with PANDAS-show a higher proportion of a specific B-lymphocyte alloantigen detected with monoclonal antibodies D8/D17 [82,83]. Consequently, some authors tried determining whether the monoclonal antibody D8/D17 could also be used as an OCD marker. The D8/D17 mean value was shown to be higher in OCD or Tourette's child populations vs. control subjects [80], and, as no difference was found between Tourette syndrome and OCD patients in D8/D17 values, it was hypothesized that it could be 
a marker for OCD in children [80]. Although these results were replicated [74,77], there is still debate surrounding this topic $[71,73,81,84]$ (Table 2).

However, this higher proportion of B-lymphocyte alloantigen detected with monoclonal antibody D8/D17 found in some OCD patients could be a promising way of classifying patients in specific subgroups of OCD (patients with a high D8/D17 value vs. OCD patients without) and could, thus, be a promising line for proposing more specific treatments for these particular patients.

\subsection{White Blood Cells}

As with cytokines, very contrasting results were found for white blood cells. Some studies found a higher number of CD8+ (cluster od differentiation) lymphocytes and a lower number of CD4+ lymphocytes in OCD patients [76], whereas others did not [85,86] (Table 3). Furthermore, other studies concerning different white blood cells (monocytes or NK cells (natural killer cells)) also found different results $[28,35,87]$ (Table 3 ). While cytokines are studied intensively in the context of OCD, more studies will need to be done specifically on white-blood-cell counts and activity.

Table 3. White blood cells and OCD.

\begin{tabular}{|c|c|c|c|}
\hline \multicolumn{4}{|c|}{ "White Blood Cells" OR “Total Blood Count” AND (OCD OR “Obsessive Compulsive Disorder”) } \\
\hline Authors, Date & Subjects & Main Results & Significance \\
\hline $\begin{array}{l}\text { Atmaca M. et al. } \\
\quad(2011)[85]\end{array}$ & $\begin{array}{c}30 \text { OCD } \\
\text { patients } \\
30 \text { controls }\end{array}$ & -> OCD patients neutrophils < control neutrophils & $p<0.05$ \\
\hline \multicolumn{4}{|c|}{ lymphocyte AND (“obsessive compulsive disorder" OR OCD) } \\
\hline \multirow{2}{*}{$\begin{array}{l}\text { Marazziti D. et al. } \\
\quad(2009)[88]\end{array}$} & \multirow{2}{*}{$\begin{array}{l}18 \mathrm{OCD} \\
\text { patients }\end{array}$} & -> CD8+ lymphocytes cells decreased after treatment & $p=0.004$ \\
\hline & & -> CD4+ lymphocytes increased after treatment & $p=0.005$ \\
\hline $\begin{array}{l}\text { Denys D. et al. } \\
\text { (2006) [87] }\end{array}$ & $\begin{array}{l}42 \mathrm{OCD} \\
\text { patients }\end{array}$ & $\begin{array}{l}\text { No effect of paroxetine or venlafaxine on TNF- } \alpha \text {, IL-4, IL-6, IL-10, } \\
\text { IFN- } \gamma \text {, NK cell activity, monocytes, T-cells, and B-cells percentages }\end{array}$ & \\
\hline $\begin{array}{l}\text { Denys D. et al. } \\
\text { (2004) [28] }\end{array}$ & \multicolumn{3}{|c|}{ Cf. cytokines AND (OCD OR “obsessive compulsive disorder”) } \\
\hline $\begin{array}{l}\text { Marazziti D. et al. } \\
\text { (2003) [89] }\end{array}$ & $\begin{array}{l}10 \text { OCD } \\
\text { patients } \\
10 \text { controls }\end{array}$ & $\begin{array}{l}->\text { OCD patients (3)H-paroxetine-binding density }<\text { controls } \\
\text { (3)H-paroxetine-binding density }\end{array}$ & $p=0.0001$ \\
\hline $\begin{array}{l}\text { Eisen JL. et al. } \\
\text { (2001) [73] }\end{array}$ & \multicolumn{3}{|c|}{ Cf. antibody AND (OCD OR “obsessive compulsive disorder") } \\
\hline $\begin{array}{l}\text { Murphy TK. et al. } \\
\text { (2001) [74] }\end{array}$ & \multicolumn{3}{|c|}{ Cf. antibody AND (OCD OR “obsessive compulsive disorder") } \\
\hline $\begin{array}{l}\text { Marazziti D. et al. } \\
\text { (2001) [90] }\end{array}$ & $\begin{array}{c}10 \text { OCD } \\
\text { patients } \\
15 \text { controls }\end{array}$ & \multicolumn{2}{|l|}{ Presence of 5-HT2C and 5-HT2A mRNAs in patients and controls } \\
\hline $\begin{array}{l}\text { Rocca P. et al. } \\
\text { (2000) [91] }\end{array}$ & $\begin{array}{c}15 \text { OCD } \\
\text { patients } \\
10 \text { controls }\end{array}$ & $->$ decrease of peripheral benzodiazepine receptor mRNA & $p<0.05$ \\
\hline $\begin{array}{l}\text { Marazziti D. et al. } \\
\text { (1999) [76] }\end{array}$ & & Cf. antibody AND (OCD OR “obsessive compulsive disorder") & \\
\hline \multirow{3}{*}{$\begin{array}{l}\text { Ravindran AV. et al. } \\
\text { (1999) [92] }\end{array}$} & \multirow{3}{*}{$\begin{array}{c}26 \text { OCD } \\
\text { patients } \\
16 \text { controls }\end{array}$} & -> OCD patients circulating NK cells < control circulating NK cell & $p<0.05$ \\
\hline & & No difference concerning B or T cells & \\
\hline & & No difference in circulating NK cells after treatment. & \\
\hline $\begin{array}{l}\text { Chapman F. et al. } \\
\text { (1998) [77] }\end{array}$ & & Cf. antibody AND (OCD OR "obsessive compulsive disorder") & \\
\hline $\begin{array}{l}\text { Murphy TK. et al. } \\
\text { (1997) [80] }\end{array}$ & & Cf. antibody AND (OCD OR “obsessive compulsive disorder") & \\
\hline $\begin{array}{l}\text { Swedo SE. et al. } \\
\text { (1997) [81] }\end{array}$ & & Cf. antibody AND (OCD OR “obsessive compulsive disorder”) & \\
\hline
\end{tabular}


Table 3. Cont

\begin{tabular}{|c|c|c|c|}
\hline \multicolumn{4}{|c|}{ "White Blood Cells" OR “Total Blood Count" AND (OCD OR “Obsessive Compulsive Disorder") } \\
\hline Authors, Date & Subjects & Main Results & Significance \\
\hline \multirow{2}{*}{$\begin{array}{c}\text { Barber Y et al. } \\
\text { (1996) [86] }\end{array}$} & \multirow{2}{*}{$\begin{array}{c}7 \text { OCD } \\
\text { patients } \\
9 \text { controls }\end{array}$} & No difference in lymphocytes between OCD patients and OCD & \\
\hline & & No difference in lymphocytes after treatment. & \\
\hline $\begin{array}{l}\text { Rocca P. et al. } \\
\text { (1991) [93] }\end{array}$ & $\begin{array}{c}18 \text { OCD } \\
\text { patients } \\
50 \text { controls }\end{array}$ & $\begin{array}{l}\text {-> Number of binding sites for peripheral benzodiazepine } \\
\text { receptor lower in OCD patients }\end{array}$ & $p<0.05$ \\
\hline \multicolumn{4}{|c|}{ monocytes AND ("obsessive compulsive disorder" OR OCD) } \\
\hline $\begin{array}{l}\text { Rodriguez N et al. } \\
\qquad \text { (2017) [35] }\end{array}$ & \multicolumn{3}{|c|}{ Cf. cytokines AND (OCD OR “obsessive compulsive disorder”) } \\
\hline $\begin{array}{l}\text { Denys D. et al. } \\
\text { (2006) [87] }\end{array}$ & \multicolumn{3}{|c|}{ Cf. lymphocyte AND ("obsessive compulsive disorder" OR OCD) } \\
\hline $\begin{array}{l}\text { Denys D. et al. } \\
\text { (2004) [28] }\end{array}$ & \multicolumn{3}{|c|}{ Cf. lymphocyte AND (“obsessive compulsive disorder" OR OCD) } \\
\hline $\begin{array}{l}\text { Weizman R. et al. } \\
\text { (1996) [20] }\end{array}$ & \multicolumn{3}{|c|}{ Cf. cytokines AND (OCD OR “obsessive compulsive disorder”) } \\
\hline \multicolumn{4}{|c|}{ NK cells" AND (“obsessive compulsive disorder" OR OCD) } \\
\hline $\begin{array}{l}\text { Denys D. et al. } \\
\text { (2004) [28] }\end{array}$ & \multicolumn{3}{|c|}{ Cf. lymphocyte AND ("obsessive compulsive disorder" OR OCD) } \\
\hline $\begin{array}{l}\text { Ravindran V. et al. } \\
\text { (1999) [92] }\end{array}$ & \multicolumn{3}{|c|}{ Cf. lymphocyte AND ("obsessive compulsive disorder" OR OCD) } \\
\hline
\end{tabular}

\section{Infections and OCD}

Here, we describe two of these infectious etiological factors (Table 4), and we discuss some possible mechanisms via which these infectious agents could lead to OCD, and hence, why these infection contexts could be considered as specific OCD subtypes.

Table 4. Infectious agents and OCD.

\begin{tabular}{|c|c|c|c|}
\hline \multicolumn{4}{|c|}{ Infection AND (OCD OR “Obsessive Compulsive Disorder”) } \\
\hline Authors, Date & Subjects & Mains Results & Significance \\
\hline $\begin{array}{l}\text { Ursoiu F. et al. } \\
\text { (2018) [94] }\end{array}$ & 101 HIV patients & No association between HIV and OCD & \\
\hline $\begin{array}{l}\text { Akaltun I. et al. } \\
\text { (2018) [52] }\end{array}$ & \multicolumn{3}{|c|}{ Cf. antibody AND (OCD OR “obsessive compulsive disorder") } \\
\hline $\begin{array}{c}\text { Flegr J et al. (2017) } \\
\text { [54] }\end{array}$ & \multicolumn{3}{|c|}{ Cf. antibody AND (OCD OR "obsessive compulsive disorder") } \\
\hline $\begin{array}{c}\text { Sutterland AL. et al. } \\
\text { (2015) [14] } \\
\text { Meta-analysis }\end{array}$ & \multicolumn{3}{|c|}{ Cf. antibody AND (OCD OR “obsessive compulsive disorder") } \\
\hline $\begin{array}{l}\text { Nicolini H. et al. } \\
\text { (2015) [55] }\end{array}$ & \multicolumn{3}{|c|}{ Cf. antibody AND (OCD OR “obsessive compulsive disorder") } \\
\hline $\begin{array}{l}\text { Miman O. et al. } \\
\text { (2010) [63] }\end{array}$ & \multicolumn{3}{|c|}{ Cf. antibody AND (OCD OR “obsessive compulsive disorder") } \\
\hline $\begin{array}{c}\text { Dale RC. et al. } \\
\text { (2004) [95] }\end{array}$ & $\begin{array}{l}40 \text { patients with } \\
\text { post-streptococcal } \\
\text { dyskinesias }\end{array}$ & $->27.5 \%$ of these patients suffered from OCD & \\
\hline
\end{tabular}


Table 4. Cont.

\begin{tabular}{|c|c|c|c|}
\hline \multicolumn{4}{|c|}{ Infection AND (OCD OR “Obsessive Compulsive Disorder”) } \\
\hline Authors, Date & Subjects & Mains Results & Significance \\
\hline $\begin{array}{l}\text { Giulino L. et al. } \\
\text { (2002) [96] }\end{array}$ & 83 OCD patients & $\begin{array}{l}\text {-> OCD patients with upper respiratory infection } \\
\text { had more sudden onset than patients without upper } \\
\text { respiratory infection } \\
\text { No difference concerning tic or ADHD comorbidity } \\
\text { between OCD patients with or without upper } \\
\text { respiratory infection. }\end{array}$ & $p=0.02$ \\
\hline $\begin{array}{l}\text { Lougee L. et al. } \\
\quad(2000)[97]\end{array}$ & $\begin{array}{c}54 \text { PANDAS/OCD or tic } \\
\text { patients } \\
139 \text { first relatives }\end{array}$ & $\begin{array}{l}->26 \% \text { of OCD patients had a relative suffering from } \\
\text { OCD }\end{array}$ & \\
\hline \multicolumn{4}{|c|}{ lyme AND ("obsessive compulsive disorder" OR OCD) } \\
\hline $\begin{array}{l}\text { Johnco C. et al. } \\
\text { (2018) [98] }\end{array}$ & $\begin{array}{l}147 \text { patients with Lyme } \\
\text { disease }\end{array}$ & $\begin{array}{l}->84 \% \text { of patients reported obsessive compulsive } \\
\text { symptoms } \\
->90.9 \% \text { of patients reported gradual onset of } \\
\text { symptoms } \\
->47 \% \text { of patients were treated with psychotropic } \\
\text { treatment and } 76.9 \% \text { of them presented at least } \\
\text { partial improvement } \\
\rightarrow>50.9 \% \text { of patients treated with antibiotics reported } \\
\text { at least partial improvement in symptoms }\end{array}$ & \\
\hline \multicolumn{4}{|c|}{ Streptococcus AND (OCD OR “obsessive compulsive disorder") } \\
\hline $\begin{array}{l}\text { Stagi S. et al. (2018) } \\
\text { [99] }\end{array}$ & $\begin{array}{l}179 \text { PANDAS/OCD or } \\
\text { tic patients }\end{array}$ & $->$ reduced vitamin D in PANDAS patients & $p<0.0001$ \\
\hline
\end{tabular}

\begin{tabular}{|c|c|c|c|}
\hline \multirow{2}{*}{$\begin{array}{l}\text { Mataix-Cols } \\
\text { D. et al. (2017) [53] } \\
\\
\text { Calaprice D. et al. } \\
\text { (2017) [100] }\end{array}$} & \multicolumn{3}{|c|}{ Cf. antibody AND (OCD OR “obsessive compulsive disorder") } \\
\hline & 698 PANS patients & $\begin{array}{l}\text {-> age of onset between } 7 \text { and } 8 \text { years } \\
->88 \% \text { of sudden onset } \\
->87 \% \text { of patients presented recurrences } \\
->94 \% \text { of patients presented a history of OCD } \\
->71 \% \text { with motor tics and } 57 \% \text { with vocal tics }\end{array}$ & \\
\hline $\begin{array}{l}\text { Wang HC. et al. } \\
\text { (2016) [101] }\end{array}$ & $\begin{array}{l}2596 \text { patients infected } \\
\text { with GAS } \\
25960 \text { controls }\end{array}$ & $\begin{array}{l}\text {-> increased risk of tic disorder in GAS infected } \\
\text { patients }\end{array}$ & No full access \\
\hline
\end{tabular}

\begin{tabular}{|c|c|c|c|}
\hline $\begin{array}{l}\text { Nicolini H. et al. } \\
\text { (2015) [55] }\end{array}$ & \multicolumn{3}{|c|}{ Cf. antibody AND (OCD OR “obsessive compulsive disorder”) } \\
\hline $\begin{array}{l}\text { Frankovich J. et al. } \\
\text { (2015) [57] }\end{array}$ & \multicolumn{3}{|c|}{ Cf. antibody AND (OCD OR “obsessive compulsive disorder") } \\
\hline $\begin{array}{l}\text { Ebrahimi Taj F. et al. } \\
\text { (2015) [59] }\end{array}$ & \multicolumn{3}{|c|}{ Cf. antibody AND (OCD OR “obsessive compulsive disorder") } \\
\hline $\begin{array}{l}\text { Murphy TK. et al. } \\
\text { (2012) [61] }\end{array}$ & \multicolumn{3}{|c|}{ Cf. antibody AND (OCD OR “obsessive compulsive disorder") } \\
\hline $\begin{array}{l}\text { Leckman JF. et al. } \\
\text { (2011) [62] }\end{array}$ & \multicolumn{3}{|c|}{ Cf. antibody AND (OCD OR “obsessive compulsive disorder") } \\
\hline $\begin{array}{l}\text { Murphy TK. et al. } \\
\text { (2010) [102] }\end{array}$ & 107 OCD or tic patients & $\begin{array}{l}->17.8 \% \text { of patients had mother suffering from } \\
\text { autoimmune disease }\end{array}$ & \\
\hline $\begin{array}{l}\text { Gause C. et al. } \\
\text { (2009) [64] }\end{array}$ & \multicolumn{3}{|c|}{ Cf. antibody AND (OCD OR “obsessive compulsive disorder") } \\
\hline $\begin{array}{l}\text { Kurlan R. et al. } \\
\text { (2008) [103] }\end{array}$ & $\begin{array}{l}40 \text { PANDAS/OCD or tic } \\
\text { patients } \\
40 \text { non-PANDAS/OCD } \\
\text { or tics }\end{array}$ & $\begin{array}{l}\text { No difference in the number of exacerbations (but } \\
\text { a strong tendency for increased exacerbation risk, } p= \\
0.07) \text {. } \\
->\text { more frequent GAS infection associated with } \\
\text { exacerbation }\end{array}$ & $p=0.002$ \\
\hline $\begin{array}{l}\text { Dale RC. et al. } \\
\text { (2004) [95] }\end{array}$ & \multicolumn{3}{|c|}{ Cf. infection AND (OCD OR “obsessive compulsive disorder") } \\
\hline $\begin{array}{l}\text { Luo F. et al. (2004) } \\
\text { [70] }\end{array}$ & \multicolumn{3}{|c|}{ Cf. antibody AND (OCD OR “obsessive compulsive disorder") } \\
\hline
\end{tabular}


Table 4. Cont.

\begin{tabular}{|c|c|c|c|}
\hline \multicolumn{4}{|c|}{ Infection AND (OCD OR “Obsessive Compulsive Disorder”) } \\
\hline Authors, Date & Subjects & Mains Results & Significance \\
\hline $\begin{array}{l}\text { Pavone P. et al. } \\
\text { (2004) [68] }\end{array}$ & \multicolumn{3}{|c|}{ Cf. antibody AND (OCD OR “obsessive compulsive disorder") } \\
\hline $\begin{array}{l}\text { Murphy TK. et al. } \\
\text { (2004) [69] }\end{array}$ & \multicolumn{3}{|c|}{ Cf. antibody AND (OCD OR "obsessive compulsive disorder") } \\
\hline $\begin{array}{l}\text { Giulino L. et al. } \\
\text { (2002) [96] }\end{array}$ & \multicolumn{3}{|c|}{ Cf. infection AND (OCD OR “obsessive compulsive disorder") } \\
\hline $\begin{array}{l}\text { Murphy TK. et al. } \\
\text { (2001) [74] }\end{array}$ & \multicolumn{3}{|c|}{ Cf. antibody AND (OCD OR "obsessive compulsive disorder") } \\
\hline $\begin{array}{l}\text { Lougee L. et al. } \\
\text { (2000) [97] }\end{array}$ & \multicolumn{3}{|c|}{ Cf. infection AND (OCD OR “obsessive compulsive disorder") } \\
\hline $\begin{array}{l}\text { Giedd JN. et al. } \\
\text { (2000) [104] }\end{array}$ & $\begin{array}{l}34 \text { PANDAS/OCD or tics } \\
82 \text { controls }\end{array}$ & $\begin{array}{l}\text {-> PANDAS patients mean caudate volume }> \\
\text { controls mean caudate volume } \\
\text {-> PANDAS patients mean putamen volume > } \\
\text { controls mean putamen volume } \\
\text {-> PANDAS patients mean globus pallidus volume > } \\
\text { controls mean globus pallidus volume } \\
\text { No difference for thalamus and total brain volume }\end{array}$ & $\begin{array}{l}p=0.004 \\
p=0.02 \\
p=0.02\end{array}$ \\
\hline $\begin{array}{l}\text { Swedo SE. et al. } \\
\text { (1998) [105] }\end{array}$ & 50 PANDAS patients & $\begin{array}{l}\text {-> Mean age at onset: } 7.4 \text { years } \\
\text {-> tics and OCD: } 64 \% \text {; tics only: } 16 \% \text { and OCD only: } \\
20 \% \\
\text {-> ADHD comorbidity: } 40 \% \text {, ODD comorbidity: } 40 \% \text {, } \\
\text { MDD comorbidity: } 36 \%\end{array}$ & \\
\hline
\end{tabular}

\begin{tabular}{cc}
\hline $\begin{array}{c}\text { Murphy TK. et al. } \\
\text { (1997) [80] }\end{array}$ & Cf. antibody AND (OCD OR “obsessive compulsive disorder") \\
\hline $\begin{array}{c}\text { Akaltun I. et al. } \\
\text { (2018) [52] }\end{array}$ & toxoplasma (OCD OR “obsessive compulsive disorder") \\
\hline $\begin{array}{c}\text { Flegr J et al. (2017) } \\
\text { [54] }\end{array}$ & Cf. antibody AND (OCD OR “obsessive compulsive disorder") \\
\hline $\begin{array}{c}\text { Sutterland AL. et al. } \\
(2015) \text { [14] }\end{array}$ & Cf. antibody AND (OCD OR “obsessive compulsive disorder") \\
\hline $\begin{array}{c}\text { Miman O. et al. } \\
\text { (2010) [63] }\end{array}$ & Cf. antibody AND (OCD OR “obsessive compulsive disorder") \\
\hline
\end{tabular}

$\mathrm{ADHD}=$ attention deficit/hyperactivity disorder; GAS = Group A streptococcus; HIV = human immunodeficiency virus; $\mathrm{MDD}=$ major depressive disorder; $\mathrm{ODD}=$ oppositional defiant disorder; PANDAS = pediatric autoimmune neuropsychological disorders associated with streptococcal infection; PANS = pediatric acute-onset neuropsychiatric syndrome.

\subsection{Streptococcal Infection}

Streptococcus pyogenes is a bacterial group that can lead to several pathologies such as pharyngitis, scarlet fever, or erysipelas [106]. Among these diseases, rheumatic fever is the one we were interested in. This disease is characterized by elevated ASO (anti-streptolysin O) or anti-DNAse B antibody levels [107], and it affects the heart, skin, bone joints, and CNS [108,109]. The Jones criteria are usually used to make the diagnosis. They consist of carditis, arthritis, chorea, erythema marginatum, and subcutaneous nodules with evidence of S. pyogenes infection $[108,109]$. S. pyogenes can, thus, affect the nervous system through choreic movements. This chorea, called Sydenham's chorea [110,111], is characterized by involuntary movements which are irregular, rapid, and transient, and which are typically manifested in the extremities [111,112]. Sydenham's chorea is characterized by antibodies found in the basal ganglia that react with $\mathrm{N}$-acetyl-beta-D-glucosamine of S. pyogenes, and with lysoganglioside and tubulin of the brain [111,113]. This cross-reaction is made possible by a mimicry process [111]. Furthermore, it was shown recently by Cox and colleagues that these antibodies could react with the D2-receptor (D2R) complex, which could be causal in Sydenham's chorea, as risperidone 
reverses this movement disorder [114]. In summary, antibodies that originally target S. pyogenes may also attack the patient's brain.

Since the basal ganglia (where Sydenham's chorea antibodies are found) appear to be a key region in OCD neurobiology [1,3], one could imagine that antibodies against basal ganglia (which seems the case in PANDAS [68]) could impair their functioning and lead to OCD symptoms in some conditions. In this context, it is notable that OCD may be associated with Sydenham's chorea [115]. In addition to this association, the concept of PANDAS (pediatric autoimmune neuropsychological disorder associated with streptococcal infection) was originally defined by Swedo et al. in 1998 [105] as follows: presence of OCD or tic disorder, symptom onset between the age of three and puberty, exacerbation of symptoms associated with streptococcal infection, and presence of neurological abnormalities during symptom exacerbation, but in the absence of frank chorea which would suggest Sydenham's chorea [105]. This original description of PANDAS was modified in 2012 by Swedo et al. to become PANS (pediatric acute-onset neuropsychiatric syndrome, with abrupt onset of OCD or severely restricted food intake and presence of additional neuropsychiatric symptoms such as anxiety, emotional liability, etc.) [13]. PANDAS and PANS could, thus, constitute a specific OCD subgroup for which the underlying physiological mechanism could be the same, that is to say, an autoantibody against basal ganglia neurons $[110,113]$.

However, no D2R antibodies were found in PANDAS patients [12]. Cox et al. recently studied patients with tic disorders or OCD or both, and with a history of streptococcal infection [58]. They found that these patients as a whole presented elevated levels of anti D1-receptor (D1R) antibodies in the serum (with elevated anti-lysoganglioside antibodies) compared to controls. As in Sydenham's chorea, anti-lysoganglioside antibodies seem to be involved [58,65] (Table 4).

Recently, antibodies in children suffering from PANDAS were found to bind more to cholinergic interneurons of mice than control antibodies when mice were infused with patient and control serum in their striatum [116]. Taken together, these results raise the question of the proportions of dopamine receptor subtypes and the role of cholinergic interneurons in OCD and more particularly in PANDAS, which is a good example of the multiple etiologies of OCD. It is one of the rare clearly identified etiological factors of OCD. About $5 \%$ of pediatric OCD patients meet the criteria for PANDAS (or PANS) [117] and it is important to distinguish this etiology from others in OCD patients. Indeed, the prognosis of PANDAS seems relatively good, as Leon et al. found that $88 \%$ of children originally suffering from PANDAS with moderate-to-severe OCD presented no OCD symptoms $(55 \%)$ or only subclinical symptoms (33\%) after approximately three years of follow-up [118] (Table 5). This result of a good prognosis is confirmed by Murphy et al. [61], but not by Frankovich et al. [57] (Table 5). By contrast, $48 \%$ of OCD patients were found to be still symptomatic after 30 years [119]. However, as this study began in 1954, and PANDAS patients, which represent about $5 \%$ of OCD patients, were first described in 1998 [105,117], one may hypothesize that PANDAS and non-PANDAS OCD patients were pooled together. Furthermore, treatment of PANDAS (described below) is not identical to OCD treatment. Prophylactic antibiotics or antibiotic treatment, anti-inflammatory treatment, and immunoglobulin, indicated in PANDAS treatment, are not prescribed in "idiopathic OCD" [118,120-125]. Therefore, it would be important to recognize and adequately treat PANDAS within a personalized medical setting. 
Table 5. Specific immunological treatment in OCD.

\begin{tabular}{|c|c|c|c|}
\hline \multicolumn{4}{|c|}{ (PANDAS OR PANS) AND Treatment AND (OCD OR “Obsessive Compulsive Disorder”) } \\
\hline Authors, Date & Subjects & Main Results & Significance \\
\hline \multirow{4}{*}{$\begin{array}{l}\text { Leon J. et al. (2018) } \\
\text { [118] }\end{array}$} & \multirow{4}{*}{33 PANDAS patients } & Follow-up lasted between 2.2 and 4.8 years & \\
\hline & & Initially, all patients treated with antibiotics & \\
\hline & & $\begin{array}{l}\text { During the follow-up period, } 45 \% \text { of patients } \\
\text { took psychotropic treatments }\end{array}$ & \\
\hline & & $\begin{array}{l}\text { At the time of follow-up, } 18 \text { patients presented } \\
\text { no symptoms, } 11 \text { only subclinical symptoms, } \\
3 \text { moderate symptoms, and } 1 \text { severe symptom. }\end{array}$ & \\
\hline \multirow{5}{*}{$\begin{array}{l}\text { Calaprice D. et al. } \\
\text { (2018) [120] }\end{array}$} & \multirow{5}{*}{698 PANS patients } & $\begin{array}{l}675 \text { patients treated with antibiotics, } 437 \text { with } \\
\text { anti-inflammatories, } 378 \text { with psychotropic } \\
\text { treatments }\end{array}$ & \\
\hline & & $\begin{array}{l}52 \% \text { of "very effective" treatments with } \\
\text { antibiotics }\end{array}$ & \\
\hline & & $\begin{array}{l}\text { NSAIDs were at least "somewhat effective" for } \\
80 \% \text { of patients }\end{array}$ & \\
\hline & & $\begin{array}{l}\text { Steroids were at least "somewhat effective" for } \\
72 \% \text { of patients }\end{array}$ & \\
\hline & & $\begin{array}{l}\text { IVIG were at least "somewhat effective" for } 74 \% \\
\text { of patients }\end{array}$ & \\
\hline \multirow{2}{*}{$\begin{array}{l}\text { Brown K. et al. } \\
\text { (2017) [121] }\end{array}$} & \multirow[t]{2}{*}{98 PANS patients } & $\begin{array}{l}\rightarrow \text { duration of symptomatic periods treated with } \\
\text { steroids }<\text { duration of symptomatic periods of } \\
\text { non-treated patients }\end{array}$ & $p<0.001$ \\
\hline & & $\begin{array}{l}\text {-> shorter symptomatic periods when initially } \\
\text { treated with steroids }\end{array}$ & $p<0.01$ \\
\hline \multirow{2}{*}{$\begin{array}{l}\text { Brown KD. et al. } \\
\text { (2017) [126] }\end{array}$} & \multirow[t]{2}{*}{95 PANS patients } & $\begin{array}{l}\text {-> Symptomatic periods treated with NSAID } \\
\text { lasted shorter than non-treated symptomatic } \\
\text { periods }\end{array}$ & $p<0.0001$ \\
\hline & & $\begin{array}{l}->\text { the more the duration without treatment is } \\
\text { short, the more symptomatic period were short }\end{array}$ & $p=0.02$ \\
\hline \multirow{3}{*}{$\begin{array}{l}\text { Spartz EJ. et al. } \\
\text { (2017) [122] }\end{array}$} & \multirow{3}{*}{159 PANS patients } & $\begin{array}{l}\text { No clinical data allow to distinguish responders } \\
\text { and non-responders to NSAIDs }\end{array}$ & \\
\hline & & $\begin{array}{l}31 \% \text { of patients with NSAID increases reported } \\
\text { improvement in symptoms }\end{array}$ & \\
\hline & & $\begin{array}{l}35 \% \text { of patients with NSAID removal reported } \\
\text { symptom increases after removal }\end{array}$ & \\
\hline \multirow{2}{*}{$\begin{array}{l}\text { Murphy TK. et al. } \\
\text { (2017) [123] }\end{array}$} & \multirow{2}{*}{$\begin{array}{c}31 \text { PANS patients } \\
\text { (17 with azithromycin, } 14 \\
\text { with placebo) }\end{array}$} & $\begin{array}{l}\text {-> azithromycin group improvement }> \\
\text { non-azithromycin group (CGI) }\end{array}$ & $p=0.003$ \\
\hline & & No difference on CY-BOCS & \\
\hline $\begin{array}{l}\text { Calaprice D. et al. } \\
\text { (2017) [100] }\end{array}$ & Cf. Streptoco & cus AND (OCD OR "obsessive compulsive disorder") & \\
\hline \multirow[t]{2}{*}{$\begin{array}{l}\text { Williams KA. et al. } \\
\quad \text { (2016) [124] }\end{array}$} & \multirow{2}{*}{$\begin{array}{l}35 \text { PANDAS patients } \\
(\text { IVIG group }=17 \\
\text { placebo group }=18 \text { ) }\end{array}$} & $\begin{array}{l}\text {-> At week } 6 \text { (double blind phase): no difference } \\
\text { between groups (CY-BOCS) }\end{array}$ & $p<0.0001$ \\
\hline & & -> Improvement after open label IVIG (CY-BOCS) & \\
\hline $\begin{array}{l}\text { Nadeau JM. et al. } \\
\text { (2015) [127] }\end{array}$ & $\begin{array}{l}11 \text { PANS patients } \\
\text { partially responder to } \\
\text { antibiotics }\end{array}$ & -> Improvement after CBT (CY-BOCS) & $p=0.01$ \\
\hline $\begin{array}{l}\text { Nicolini H. et al. } \\
\text { (2015) [55] }\end{array}$ & \multicolumn{3}{|c|}{ Cf. antibody AND (OCD OR “obsessive compulsive disorder") } \\
\hline $\begin{array}{l}\text { Frankovich J. et al. } \\
\text { (2015) [57] }\end{array}$ & \multicolumn{3}{|c|}{ Cf. antibody AND (OCD OR “obsessive compulsive disorder") } \\
\hline $\begin{array}{l}\text { Latimer ME. et al. } \\
\quad(2015)[128]\end{array}$ & 35 PANDAS patients & $\begin{array}{l}->6 \text { months after therapeutic plasma apheresis: } \\
\text { improvement of } 65 \% \text { (local questionnaire) }\end{array}$ & \\
\hline
\end{tabular}


Table 5. Cont.

\begin{tabular}{|c|c|c|c|}
\hline \multicolumn{4}{|c|}{ (PANDAS OR PANS) AND Treatment AND (OCD OR “Obsessive Compulsive Disorder”) } \\
\hline Authors, Date & Subjects & Main Results & Significance \\
\hline \multirow{2}{*}{$\begin{array}{l}\text { Demesh D. et al. } \\
\text { (2015) [129] }\end{array}$} & \multirow{2}{*}{10 PANDAS patients } & $\begin{array}{l}\text {-> Improvement in symptom intensity after } \\
\text { antibiotic treatment (local questionnaire) }\end{array}$ & $p=0.03$ \\
\hline & & $\begin{array}{l}\text {-> Improvement in symptom intensity after } \\
\text { tonsillectomy (local questionnaire) }\end{array}$ & $p=0.02$ \\
\hline $\begin{array}{l}\text { Ebrahimi Taj F. et al. } \\
\text { (2015) [59] }\end{array}$ & \multicolumn{3}{|c|}{ Cf. antibody AND (OCD OR “obsessive compulsive disorder") } \\
\hline $\begin{array}{l}\text { Pavone P. et al. } \\
\text { (2014) [130] }\end{array}$ & $\begin{array}{l}120 \text { PANDAS patients } \\
\text { (56 patients with } \\
\text { tonsillectomy or } \\
\text { adrenotonsillectomy, } 64 \\
\text { without) }\end{array}$ & $\begin{array}{l}\text { No difference concerning symptomatology, } \\
\text { streptococcal antibodies or anti-neural antibodies } \\
\text { (evaluation every two months for } 2 \text { years) }\end{array}$ & \\
\hline $\begin{array}{l}\text { Murphy TK. et al. } \\
\text { (2012) [61] }\end{array}$ & \multicolumn{3}{|c|}{ Cf. antibody AND (OCD OR “obsessive compulsive disorder") } \\
\hline \multirow{5}{*}{$\begin{array}{l}\text { Bernstein GA. et al. } \\
\quad(2010)[131]\end{array}$} & \multirow{5}{*}{$\begin{array}{l}21 \text { PANDAS patients } \\
18 \text { non-PANDAS OCD } \\
\text { patients }\end{array}$} & \multicolumn{2}{|l|}{ No difference concerning age at onset of OCD } \\
\hline & & \multicolumn{2}{|l|}{ No difference concerning CY-BOCS score } \\
\hline & & $\begin{array}{l}\text {-> PANDAS patients YGTSS score }> \\
\text { non-PANDAS patients YGTSS score }\end{array}$ & $p=0.013$ \\
\hline & & \multicolumn{2}{|l|}{$\begin{array}{l}\text { No difference concerning ASO or anti-DNase B } \\
\text { titers }\end{array}$} \\
\hline & & $\begin{array}{l}\text {-> In non-PANDAS OCD patients, separation } \\
\text { anxiety disorder and social phobia are more } \\
\text { frequent }\end{array}$ & $\begin{array}{l}p=0.02 \text { and } \\
0.047 \\
\text { respectively }\end{array}$ \\
\hline $\begin{array}{l}\text { Storch EA. et al. } \\
\text { (2006) [132] }\end{array}$ & 7 PANDAS patients & -> CY-BOCS improvement after 3 weeks of CBT & $p=0.018$ \\
\hline $\begin{array}{l}\text { Snider LA. et al. } \\
\text { (2005) [133] }\end{array}$ & 23 PANDAS patients & $\begin{array}{l}\text {-> Decrease in number of symptom exacerbations } \\
\text { with antibiotic treatment }\end{array}$ & $p<0.01$ \\
\hline $\begin{array}{l}\text { Garvey MA. et al. } \\
\quad \text { (1999) [134] }\end{array}$ & $\begin{array}{l}37 \text { PANDAS patients } \\
\text { (double blind and cross } \\
\text { over design) }\end{array}$ & $\begin{array}{l}\text { No difference in symptoms following antibiotic } \\
\text { treatment }\end{array}$ & \\
\hline $\begin{array}{l}\text { Swedo SE. et al. } \\
\text { (1998) [105] }\end{array}$ & \multicolumn{3}{|c|}{ Cf. Streptococcus AND (OCD OR “obsessive compulsive disorder") } \\
\hline \multicolumn{4}{|c|}{ NSAID and (OCD OR “obsessive-compulsive disorder") } \\
\hline $\begin{array}{l}\text { Brown KD. et al. } \\
\text { (2017) [126] }\end{array}$ & \multicolumn{3}{|c|}{ Cf. (PANDAS OR PANS) AND treatment AND (OCD OR "obsessive compulsive disorder") } \\
\hline $\begin{array}{l}\text { Spartz EJ. et al. } \\
\text { (2017) [122] }\end{array}$ & \multicolumn{3}{|c|}{ Cf. (PANDAS OR PANS) AND treatment AND (OCD OR "obsessive compulsive disorder") } \\
\hline $\begin{array}{l}\text { Shalbafan M. et al. } \\
\text { (2015) [135] }\end{array}$ & $\begin{array}{l}25 \text { OCD patients with } \\
\text { celecoxib }(+S R I) \\
25 \text { OCD patients with } \\
\text { placebo (+SRI) }\end{array}$ & $\begin{array}{l}->\text { lower CY-BOCS score at week } 10 \text { in celecoxib } \\
\text { group than in placebo group }\end{array}$ & $p=0.047$ \\
\hline \multirow{2}{*}{$\begin{array}{l}\text { Sayyah M. et al. } \\
\text { (2011) [136] }\end{array}$} & \multirow{2}{*}{$\begin{array}{l}27 \text { OCD patients with } \\
\text { celecoxib (+fluoxetine) } \\
25 \text { OCD patients with } \\
\text { placebo (+fluoxetine) }\end{array}$} & $\begin{array}{l}\rightarrow \text { lower CY-BOCS score at week } 8 \text { in celecoxib } \\
\text { group than in placebo group }\end{array}$ & $p=0.037$ \\
\hline & & $\begin{array}{l}\text {-> significant effect of time-by-treatment } \\
\text { interaction in ANOVA }\end{array}$ & $p=0.018$ \\
\hline & \multicolumn{3}{|c|}{ "anti-inflammatory" and (OCD OR "obsessive-compulsive disorder") } \\
\hline $\begin{array}{l}\text { Calaprice D. et al. } \\
(2018)[120]\end{array}$ & \multicolumn{3}{|c|}{ Cf. (PANDAS OR PANS) AND treatment AND (OCD OR "obsessive compulsive disorder") } \\
\hline $\begin{array}{l}\text { Brown K. et al. } \\
\text { (2017) [121] }\end{array}$ & \multicolumn{3}{|c|}{ Cf. (PANDAS OR PANS) AND treatment AND (OCD OR "obsessive compulsive disorder") } \\
\hline $\begin{array}{l}\text { Brown KD. et al. } \\
\text { (2017) [126] }\end{array}$ & \multicolumn{3}{|c|}{ Cf. (PANDAS OR PANS) AND treatment AND (OCD OR "obsessive compulsive disorder") } \\
\hline
\end{tabular}


Table 5. Cont.

\begin{tabular}{|c|c|c|c|}
\hline \multicolumn{4}{|c|}{ (PANDAS OR PANS) AND Treatment AND (OCD OR “Obsessive Compulsive Disorder”) } \\
\hline Authors, Date & Subjects & Main Results & Significance \\
\hline $\begin{array}{l}\text { Shalbafan M. et al. } \\
\text { (2015) [135] }\end{array}$ & \multicolumn{3}{|c|}{ Cf. NSAID and (OCD OR "obsessive-compulsive disorder") } \\
\hline $\begin{array}{l}\text { Sayyah M. et al. } \\
\text { (2011) [136] }\end{array}$ & \multicolumn{3}{|c|}{ Cf. NSAID and (OCD OR "obsessive-compulsive disorder") } \\
\hline \multicolumn{4}{|c|}{ minocycline and (OCD OR “obsessive-compulsive disorder") } \\
\hline $\begin{array}{l}\text { Esalatmanesh et al. } \\
\quad \text { (2016) [137] }\end{array}$ & $\begin{array}{c}47 \text { OCD patients with } \\
\text { minocycline } \\
\text { (+fluvoxamine) } \\
47 \text { OCD patients with } \\
\text { placebo (+fluvoxamine) }\end{array}$ & $\begin{array}{l}->\text { lower Y-BOCS score at week } 10 \text { in minocylcine } \\
\text { group than in placebo group }\end{array}$ & $p=0.008$ \\
\hline $\begin{array}{l}\text { Rodriguez CI. et al. } \\
\text { (2010) [138] }\end{array}$ & $\begin{array}{l}9 \text { OCD patients with } \\
\text { minocycline (+SRI) }\end{array}$ & No effect of minocycline at week 12 & \\
\hline \multicolumn{4}{|c|}{$\mathrm{N}$-acetylcysteine and (OCD OR “obsessive-compulsive disorder") } \\
\hline $\begin{array}{l}\text { Ghanizadeh } \\
\text { A. et al. (2017) [139] }\end{array}$ & $\begin{array}{l}18 \text { OCD patients with } \\
\text { NAC (+citalopram) } \\
11 \text { OCD patients with } \\
\text { placebo (+citalopram) }\end{array}$ & $\begin{array}{l}->\text { lower Y-BOCS score at week } 12 \text { in NAC group } \\
\text { than in placebo group }\end{array}$ & $p<0.02$ \\
\hline $\begin{array}{l}\text { Costa DLC. et al. } \\
\text { (2017) [140] }\end{array}$ & $\begin{array}{l}40 \text { OCD patients } \\
\text { randomized in } 2 \text { groups: } \\
\text { NAC and placebo (no } \\
\text { access to the details) }\end{array}$ & $\begin{array}{l}\text {-> No difference between the two groups } \\
\text { concerning Y-BOCS scores. }\end{array}$ & \\
\hline $\begin{array}{l}\text { Paydary K. et al. } \\
\quad(2016)[141]\end{array}$ & $\begin{array}{l}23 \text { OCD patients with } \\
\text { NAC (+fluvoxamine) } \\
23 \text { OCD patients with } \\
\text { placebo (+fluvoxamine) }\end{array}$ & $\begin{array}{l}->\text { No difference between the two groups } \\
\text { concerning Y-BOCS at week } 10 .\end{array}$ & \\
\hline $\begin{array}{l}\text { Sarris J. et al. (2015) } \\
\text { [142] }\end{array}$ & $\begin{array}{l}22 \text { OCD patients with } \\
\text { NAC (+TAU) } \\
22 \text { OCD patients with } \\
\text { placebo (+TAU) }\end{array}$ & $\begin{array}{l}\text {-> No difference between the two groups } \\
\text { concerning Y-BOCS at week } 16 .\end{array}$ & \\
\hline $\begin{array}{l}\text { Afshar F. et al. } \\
\text { (2012) [143] }\end{array}$ & $\begin{array}{l}24 \text { OCD patients with } \\
\text { NAC (+SRI) } \\
24 \text { OCD patients with } \\
\text { placebo (+SRI) }\end{array}$ & $\begin{array}{l}->\text { lower Y-BOCS score at week } 12 \text { in NAC group } \\
\text { than in placebo group }\end{array}$ & $p=0.03$ \\
\hline
\end{tabular}

$\mathrm{ASO}=$ anti-streptolysin $\mathrm{O} ; \mathrm{CBT}=$ cognitive behavioral therapy; $\mathrm{CGI}=$ clinical global impression; CY-BOCS = Children's Yale-Brown Obsessive Compulsive Scale; IVIG = intravenous immunoglobulin; NAC = N-acetylcysteine; NSAID = non-steroidal anti-inflammatory drug; PANDAS = pediatric autoimmune neuropsychological disorders associated with streptococcal infection; PANS = pediatric acute-onset neuropsychiatric Syndrome; SRI = serotonin reuptake inhibitor; TAU = treatment as usual; Y-BOCS = Yale-Brown Obsessive Compulsive Scale; Y-GTSS = Yale Global Tic Severity Scale.

\subsection{Toxoplasma gondii}

Toxoplasma gondii is an intracellular parasite that is linked to several psychiatric disorders including schizophrenia and bipolar disorder $[144,145]$. T. gondii is also linked to OCD $[14,54,63,145]$ (Table 4). A recent study found that the presence of anti-Toxoplasma gondii IgG (immunoglobulin G) in serum was more frequent in OCD patients than in controls (the odds ratio (OR) was 4.84 (confidence intervals = 1.78-13.12) in favor of OCD) [52] (Table 4). Furthermore, in a 1991 study, Strittmatter and colleagues showed that the CNS areas most affected by T. gondii were the cerebral hemispheres (91\%) and the basal ganglia (78\%) which are implicated in OCD neurobiology [146]. There are several hypotheses regarding how $T$. gondii reaches the CNS (for a review, see the article by Ueno et al. [147]). Among these, the monocyte hypothesis is of particular interest. Indeed, the fact that $T$. gondii is found in the brain CD11b+ monocytes, which can be microglial cells (the resident monocytes of the brain) [148], suggests that $T$. gondii can invade monocytes in the peripheral blood supply and then reach the brain. 
Once in the brain and in microglia, these monocytes become activated and show increased migratory activity [149].

T. gondii infection leads to IFN- $\gamma$ (interferon) production, and then, to the induction of IDO (indolamine-2,3-dioxygenase), mainly produced by microglia and one of the main enzymes of kynurenine pathway [150-154]. This induction of IDO by T. gondii occurs firstly in parallel with the T. gondii-induced microglia activation and can secondly lead to a tryptophan depletion (since the kynurenine pathway is part of tryptophan catabolism) [149,150,155]. As tryptophan is the essential amino acid for serotonin synthesis, tryptophan depletion could interfere with OCD physiological pathways since OCD symptoms are improved with specific serotonin reuptake inhibitors (SSRIs) [156-158]. Nonetheless, we have to keep in mind that this causal tryptophan depletion hypothesis is still a matter of debate in MDD (major depressive disorder); thus, the putative T. gondii role in OCD is unclear [159].

We could also hypothesize a T. gondii action at the level of striatal dopamine receptors. T. gondii contains genes coding for tyrosine hydroxylase, and it was shown that T. gondii increases the dopamine release [160]; therefore, T. gondii could lead to OCD through dopamine release and its action on striatal D1 receptors, and then, via the activation of the direct pathway (associated with the D1 receptor [161]). Nonetheless, this hypothesis is highly speculative since interactions among D1 receptors, D2 receptors (between direct and indirect pathway), and serotonin receptors are complex, and D1 receptor downregulation could be a consequence of a D1 receptor hyper stimulation, thus leading to an inhibition of the direct pathway.

Finally, there is a neurotoxic hypothesis, via the direct neurotoxic role of quinolinic acid (produced by the kynurenine pathway) and IFN- $\gamma$ which acts as a neurotoxic agent through its action on the kynurenine pathway [162]. Therefore, one could speculate that $T$. gondii is neurotoxic for the striatal microcircuit, and thus, contributes to the occurrence of OCD symptoms.

According to these different hypotheses on the role of $T$. gondii in the genesis of OCD, some innovative treatment options might be suggested such as the use of IDO inhibitors used for some cancer treatments [163], which were already tested in some animal models of schizophrenia where such treatment seems to protect the striatum from the negative effects of kynurenine pathway activation [164].

\section{Alternative Treatments for OCD}

The above distinct etiological factors in OCD could be taken into account to develop specific treatments. Tricyclic or SSRI antidepressants are the usual treatment for OCD [165]. For refractory and severe OCD, deep brain stimulation can also be used [6]. Other treatments were also developed for specific etiological factors.

\subsection{Specific Treatment in the PANS/PANDAS Context}

Several specific treatments were studied for PANS/PANDAS patients. Intravenous immunoglobulin (IVIG) could be an effective treatment $[120,124,166]$ (Table 5); however, its effectiveness remains to be confirmed. Another treatment procedure studied was apheresis. Two studies found this treatment to be effective [128,166] (Table 5), but they suffered from limitations (absence of a control group or a limited number of patients studied), which meant no definitive conclusion could be drawn on its effectiveness in PANDAS. The effects of antibiotic treatment in PANDAS were also studied. Four studies without control groups found that antibiotics could be effective $[118,120,129,133]$ (Table 5), although a study comparing azithromycin vs. placebo as a treatment for PANS over four weeks failed to find an effect of azithromycin on OCD symptoms as measured with the Children's Yale-Brown Obsessive Compulsive Scale (CY-BOCS) [123] (Table 5). However, if streptococcal infection is still present during acute episodes of PANDAS, antibiotics are considered as the best treatment $[167,168]$. Finally, corticosteroid and nonsteroidal anti-inflammatory drugs (NSAIDs) do appear to be effective [120-122,126] (Table 5). 
Hence, several alternative specific treatments to PANDAS/PANS were studied. However, even if some of these proposed treatments seem promising, robust clinical evidence is still lacking to allow us to reach a definitive conclusion [169].

\subsection{Specific Treatment in the "Classical" OCD Context}

In addition to PANS/PANDAS, immunological treatments were also tested in "classical" OCD, that is to say, with no clearly identified etiological factor. NSAIDs show contrasting results $[135,136,170]$ (Table 5). However, in the general context of OCD with no specific etiological factors, anti-inflammatory treatment seems to have a place in the treatment strategy, which could be more precisely defined if OCD etiologies were better known. Minocycline, a specific antibiotic, is particularly interesting because of its action on microglia (see below). Minocycline was studied as a potential new pharmacological treatment for OCD, and the results were mixed: one study found that minocycline could be a good adjunctive treatment to classical OCD treatment with SSRIs [137], but another one did not find this result [138] (Table 5). Another antibiotic, cefdinir, was studied, but it showed no effectiveness on the CY-BOCS scores when compared to a placebo [171]. Finally, N-acetylcysteine (NAC), an antioxidant which has a neuroprotective role against oxidative stress, produced divergent results [139-143] (Table 5).

These different studies on immunological treatment in the PANDAS/PANS contexts or otherwise indicate that some specific treatments for different aspects of immunity could have a place in OCD treatment.

\section{Conclusions: Future Lines of Research for Etiological Immune Response Factors}

\subsection{Animal Models}

The rodent animal model is widely used in anxiety disorder studies. Rodents present many behavioral signs of anxiety in various contexts. Among these behaviors, grooming was considered by some authors as a compulsive-like behavior, due to its repetitive and sequential organization [172]. Hence, several animal models that were created by mutating genes of interest (e.g., Sapap3 mutant-mice [173]) were considered as animal models for OCD because of their excessive grooming behavior among other parameters. Hox genes are homeotic genes [174], which are responsible for the anterior posterior segmentation of the organism. They are also involved in the formation of the hematopoietic system, and Hoxb8 is especially involved in the differentiation of myeloid progenitor cells, one source of microglial cells [175]. It is, therefore, of note that, firstly, Hoxb8 mutant-mice show exacerbated grooming behavior since, in the brain, microglia are the only cells linked to Hoxb8, and secondly, that grooming could be reversed after normal bone marrow transplantation which allows Hoxb8-derived microglia to migrate to the brain [175]. These data show a direct involvement of microglia, which is an immunological component in compulsive-like behaviors. Therefore, microglia (see below) could be a promising future line of research to better understand OCD and the role of immunology in a specific OCD cluster.

Rats exposed to Streptococcus antigens show more grooming behavior than control rats [176] and offer a model within which to investigate the link between OCD neurobiology and PANDAS. Indeed, grooming behavior was found to be reversible with serotonin re-uptake inhibitors, and IgG was found in key brain areas of OCD rats (i.e., striatum, thalamus, and frontal cortex), and glutamate and dopamine levels were also found to be modified [176]. Furthermore, the amelioration of some of the previous abnormalities found in this model with an antibiotic treatment [177] is in line with other results in humans [123].

\subsection{Microglia}

Tourette syndrome is a condition close to the OCD spectrum $[178,179]$, and is well known for showing interneuron loss [180]. Interestingly, a high level of CD45, which is a marker of activated microglia, was found in Tourette's post-mortem basal ganglia [181,182]. An elevated expression 
of CCL2 (chemokine ligand 2), which is a chemokine that activates microglia, was also found in these brains [181,182], raising the question of whether the interneuron loss in Tourette syndrome is linked in some manner to microglia activation. Indeed, among the functions of microglia are synapse elimination and phagocytosis [183]. There is convergent evidence in OCD, as a recent study found microglia activation in an OCD brain employing a PET (positron emission tomography) protocol [184], which shows a potential role for inflammation and microglia in OCD neurobiology [11]. These results are consistent with the cytokine levels found in OCD patients, as activated microglia produce IL-6, IL-1 $\beta$, and TNF- $\alpha[11,181]$. This could explain the effectiveness of minocycline, which reduces microglia activation [185], as another OCD treatment in Reference [137], and highlights the importance for precision medicine to consider immunological etiological factors.

\subsection{The Importance of the Attempt to Identify Different OCD Etiologies}

As we can see (Table 6), it is likely that there are multiple etiological factors in OCD. Genetic and environmental factors clearly play a role in the emergence of OCD. Some genetic studies indicate the involvement of immune response genes in the physiological basis of OCD $[9,10,186]$. The environment could play a role through epigenetic processes [187], and could also have a more direct influence on brain function through immunological processes, as is the case with PANDAS. Furthermore, it was shown that stress may directly impact some immunological parameters [188], raising the putative role of psychological stressors through immunological responses in OCD emergence.

Table 6. Summary.

Divergent results concerning cytokines (especially IL-6, TNF- $\alpha$ ) were found between studies. These discrepancies, therefore, raise the question of different patient populations, with some patients possibly presenting with immunological deficiencies, thus explaining the discrepancies.

Antibody studies show that autoimmune factors could be specific etiologies in OCD.

Streptococcus pyogenes is already recognized as possibly leading to OCD through PANS (pediatric acute-onset neuropsychiatric syndrome), as is Toxoplasma gondii. The mechanisms leading to OCD for S. pyognes and T. gondii are still unknown, but autoimmunity seems to be involved.

According to these different possible immune etiological factors (autoimmunity, infection), some specific treatments were already tested opening the way to individualized specific treatments. An effort to clearly distinguish between the different etiological (including immunological) factors is still necessary in order to develop more effective OCD treatments

$\mathrm{IL}$ = interleukin; $\mathrm{OCD}$ = obsessive-compuslve disorder; PANS = pediatric acute-onset neuropsychiatric syndrome; $\mathrm{TNF}=$ tumor necrosis factor.

Future research should focus on these etiological factors (genetic, immunological, etc.) in order to elucidate the biological bases of OCD, and to develop prevention tools and better treatments [189], paving the way to precision individualized therapies [190] for the benefit of patients. The identification of more specific biological clusters in OCD is essential in order to advance our knowledge and treatment of OCD.

Author Contributions: H.L. and L.M. conceived and designed the research on Pubmed database; H.L. performed the research on Pubmed database, analyzed the results and wrote the paper; L.M. rearranged the text and improved the text; P.S. and A.P contributed rearrange and contributed to improvements with commentaries; J.-M.B. contributed to improvements with commentaries.

Funding: This research received no external funding.

Conflicts of Interest: The authors declare no conflicts of interest.

\section{References}

1. Pauls, D.L.; Abramovitch, A.; Rauch, S.L.; Geller, D.A. Obsessive-compulsive disorder: An integrative genetic and neurobiological perspective. Nat. Rev. Neurosci. 2014, 15, 410-424. [CrossRef] [PubMed] 
2. American Psychiatric Association; DSM-5 Task Force. Diagnostic and Statistical Manual of Mental Disorders: DSM-5, 5th ed.; American Psychiatric Association: Washington, DC, USA, 2013; 947p.

3. Abramowitz, J.S.; Taylor, S.; McKay, D. Obsessive-compulsive disorder. Lancet 2009, 374, 491-499. [CrossRef]

4. Rotge, J.Y.; Guehl, D.; Dilharreguy, B.; Cuny, E.; Tignol, J.; Bioulac, B.; Allard, M.; Burbaud, P.; Aouizerate, B. Provocation of obsessive-compulsive symptoms: A quantitative voxel-based meta-analysis of functional neuroimaging studies. J. Psychiatry Neurosci. 2008, 33, 405-412. [PubMed]

5. Haynes, W.I.; Mallet, L. High-frequency stimulation of deep brain structures in obsessive-compulsive disorder: The search for a valid circuit. Eur. J. Neurosci. 2010, 32, 1118-1127. [CrossRef] [PubMed]

6. Mallet, L.; Polosan, M.; Jaafari, N.; Baup, N.; Welter, M.L.; Fontaine, D.; du Montcel, S.T.; Yelnik, J.; Chereau, I.; Arbus, C.; et al. Subthalamic nucleus stimulation in severe obsessive-compulsive disorder. N. Engl. J. Med. 2008, 359, 2121-2134. [CrossRef] [PubMed]

7. Burguiere, E.; Monteiro, P.; Feng, G.; Graybiel, A.M. Optogenetic stimulation of lateral orbitofronto-striatal pathway suppresses compulsive behaviors. Science 2013, 340, 1243-1246. [CrossRef] [PubMed]

8. Costas, J.; Carrera, N.; Alonso, P.; Gurriaran, X.; Segalas, C.; Real, E.; Lopez-Sola, C.; Mas, S.; Gasso, P.; Domenech, L.; et al. Exon-focused genome-wide association study of obsessive-compulsive disorder and shared polygenic risk with schizophrenia. Transl. Psychiatry 2016, 6, e768. [CrossRef] [PubMed]

9. Cappi, C.; Brentani, H.; Lima, L.; Sanders, S.J.; Zai, G.; Diniz, B.J.; Reis, V.N.; Hounie, A.G.; Conceicao do Rosario, M.; Mariani, D.; et al. Whole-exome sequencing in obsessive-compulsive disorder identifies rare mutations in immunological and neurodevelopmental pathways. Transl. Psychiatry 2016, 6, e764. [CrossRef] [PubMed]

10. Rodriguez, N.; Morer, A.; Gonzalez-Navarro, E.A.; Gasso, P.; Boloc, D.; Serra-Pages, C.; Lafuente, A.; Lazaro, L.; Mas, S. Human-leukocyte antigen class ii genes in early-onset obsessive-compulsive disorder. World J. Biol. Psychiatry 2017. [CrossRef] [PubMed]

11. Frick, L.; Pittenger, C. Microglial dysregulation in OCD, tourette syndrome, and PANDAS. J. Immunol. Res. 2016, 2016, 8606057. [CrossRef] [PubMed]

12. Dale, R.C.; Merheb, V.; Pillai, S.; Wang, D.; Cantrill, L.; Murphy, T.K.; Ben-Pazi, H.; Varadkar, S.; Aumann, T.D.; Horne, M.K.; et al. Antibodies to surface dopamine-2 receptor in autoimmune movement and psychiatric disorders. Brain 2012, 135, 3453-3468. [CrossRef] [PubMed]

13. Swedo, S.E.; Leckman, J.F.; Rose, N.R. From research subgroup to clinical syndrome: Modifying the PANDAS criteria to describe PANS (pediatric acute-onset neuropsychiatric syndrome). Pediatr. Ther. 2012, 2, 1000113. [CrossRef]

14. Sutterland, A.L.; Fond, G.; Kuin, A.; Koeter, M.W.; Lutter, R.; van Gool, T.; Yolken, R.; Szoke, A.; Leboyer, M.; de Haan, L. Beyond the association. Toxoplasma gondii in schizophrenia, bipolar disorder, and addiction: Systematic review and meta-analysis. Acta Psychiatr. Scand. 2015, 132, 161-179. [CrossRef] [PubMed]

15. Baldermann, J.C.; Schuller, T.; Huys, D.; Becker, I.; Timmermann, L.; Jessen, F.; Visser-Vandewalle, V.; Kuhn, J. Deep brain stimulation for tourette-syndrome: A systematic review and meta-analysis. Brain Stimul. 2016, 9 , 296-304. [CrossRef] [PubMed]

16. Kisely, S.; Hall, K.; Siskind, D.; Frater, J.; Olson, S.; Crompton, D. Deep brain stimulation for obsessive-compulsive disorder: A systematic review and meta-analysis. Psychol. Med. 2014, 44, 3533-3542. [CrossRef] [PubMed]

17. Blomstedt, P.; Sjoberg, R.L.; Hansson, M.; Bodlund, O.; Hariz, M.I. Deep brain stimulation in the treatment of obsessive-compulsive disorder. World Neurosurg. 2013, 80, e245-e253. [CrossRef] [PubMed]

18. Hirschtritt, M.E.; Bloch, M.H.; Mathews, C.A. Obsessive-compulsive disorder: Advances in diagnosis and treatment. JAMA 2017, 317, 1358-1367. [CrossRef] [PubMed]

19. Rose-John, S. Interleukin-6 family cytokines. Cold Spring Harb. Perspect. Biol. 2018, 10. [CrossRef] [PubMed]

20. Weizman, R.; Laor, N.; Barber, Y.; Hermesh, H.; Notti, I.; Djaldetti, M.; Bessler, H. Cytokine production in obsessive-compulsive disorder. Biol. Psychiatry 1996, 40, 908-912. [CrossRef]

21. Maes, M.; Meltzer, H.Y.; Bosmans, E. Psychoimmune investigation in obsessive-compulsive disorder: Assays of plasma transferrin, IL-2 and IL-6 receptor, and IL-1 $\beta$ and IL-6 concentrations. Neuropsychobiology 1994, 30, 57-60. [CrossRef] [PubMed]

22. Cappi, C.; Muniz, R.K.; Sampaio, A.S.; Cordeiro, Q.; Brentani, H.; Palacios, S.A.; Marques, A.H.; Vallada, H.; Miguel, E.C.; Guilherme, L.; et al. Association study between functional polymorphisms in the tnf-alpha gene and obsessive-compulsive disorder. Arq. Neuropsiquiatr. 2012, 70, 87-90. [CrossRef] [PubMed] 
23. Fontenelle, L.F.; Barbosa, I.G.; Luna, J.V.; de Sousa, L.P.; Abreu, M.N.; Teixeira, A.L. A cytokine study of adult patients with obsessive-compulsive disorder. Compr. Psychiatry 2012, 53, 797-804. [CrossRef] [PubMed]

24. Fluitman, S.B.; Denys, D.A.; Heijnen, C.J.; Westenberg, H.G. Disgust affects TNF-alpha, IL-6 and noradrenalin levels in patients with obsessive-compulsive disorder. Psychoneuroendocrinology 2010, 35, 906-911. [CrossRef] [PubMed]

25. Fluitman, S.; Denys, D.; Vulink, N.; Schutters, S.; Heijnen, C.; Westenberg, H. Lipopolysaccharide-induced cytokine production in obsessive-compulsive disorder and generalized social anxiety disorder. Psychiatry Res. 2010, 178, 313-316. [CrossRef] [PubMed]

26. Hounie, A.G.; Cappi, C.; Cordeiro, Q.; Sampaio, A.S.; Moraes, I.; Rosario, M.C.; Palacios, S.A.; Goldberg, A.C.; Vallada, H.P.; Machado-Lima, A.; et al. Tnf-alpha polymorphisms are associated with obsessive-compulsive disorder. Neurosci. Lett. 2008, 442, 86-90. [CrossRef] [PubMed]

27. Konuk, N.; Tekin, I.O.; Ozturk, U.; Atik, L.; Atasoy, N.; Bektas, S.; Erdogan, A. Plasma levels of tumor necrosis factor- $\alpha$ and interleukin-6 in obsessive compulsive disorder. Mediat. Inflamm. 2007, 2007, 65704. [CrossRef] [PubMed]

28. Denys, D.; Fluitman, S.; Kavelaars, A.; Heijnen, C.; Westenberg, H. Decreased TNF-alpha and NK activity in obsessive-compulsive disorder. Psychoneuroendocrinology 2004, 29, 945-952. [CrossRef] [PubMed]

29. Monteleone, P.; Catapano, F.; Fabrazzo, M.; Tortorella, A.; Maj, M. Decreased blood levels of tumor necrosis factor-alpha in patients with obsessive-compulsive disorder. Neuropsychobiology 1998, 37, 182-185. [CrossRef] [PubMed]

30. Brambilla, F.; Perna, G.; Bellodi, L.; Arancio, C.; Bertani, A.; Perini, G.; Carraro, C.; Gava, F. Plasma interleukin-1 beta and tumor necrosis factor concentrations in obsessive-compulsive disorders. Biol. Psychiatry 1997, 42, 976-981. [CrossRef]

31. Gray, S.M.; Bloch, M.H. Systematic review of proinflammatory cytokines in obsessive-compulsive disorder. Curr. Psychiatry Rep. 2012, 14, 220-228. [CrossRef] [PubMed]

32. Colak Sivri, R.; Bilgic, A.; Kilinc, I. Cytokine, chemokine and bdnf levels in medication-free pediatric patients with obsessive-compulsive disorder. Eur. Child Adolesc. Psychiatry 2018, 27, 977-984. [CrossRef] [PubMed]

33. Simsek, S.; Yuksel, T.; Cim, A.; Kaya, S. Serum cytokine profiles of children with obsessive-compulsive disorder shows the evidence of autoimmunity. Int. J. Neuropsychopharmacol. 2016, 19, pyw027. [CrossRef] [PubMed]

34. Rao, N.P.; Venkatasubramanian, G.; Ravi, V.; Kalmady, S.; Cherian, A.; Yc, J.R. Plasma cytokine abnormalities in drug-naive, comorbidity-free obsessive-compulsive disorder. Psychiatry Res. 2015, 229, 949-952. [CrossRef] [PubMed]

35. Rodriguez, N.; Morer, A.; Gonzalez-Navarro, E.A.; Serra-Pages, C.; Boloc, D.; Torres, T.; Garcia-Cerro, S.; Mas, S.; Gasso, P.; Lazaro, L. Inflammatory dysregulation of monocytes in pediatric patients with obsessive-compulsive disorder. J. Neuroinflamm. 2017, 14, 261. [CrossRef] [PubMed]

36. Jiang, C.; Ma, X.; Qi, S.; Han, G.; Li, Y.; Liu, Y.; Liu, L. Association between tnf-alpha-238g/a gene polymorphism and ocd susceptibility: A meta-analysis. Medicine 2018, 97, e9769. [CrossRef] [PubMed]

37. Uguz, F.; Onder Sonmez, E.; Sahingoz, M.; Gokmen, Z.; Basaran, M.; Gezginc, K.; Sonmez, G.; Kaya, N.; Yilmaz, E.; Erdem, S.S.; et al. Neuroinflammation in the fetus exposed to maternal obsessive-compulsive disorder during pregnancy: A comparative study on cord blood tumor necrosis factor-alpha levels. Compr. Psychiatry 2014, 55, 861-865. [CrossRef] [PubMed]

38. Bo, Y.; Liu, S.; Yin, Y.; Wang, Z.; Cui, J.; Zong, J.; Zhang, X.; Li, X. Association study between IL-1ß-511 C/T polymorphism and obsessive-compulsive disorder (OCD) in chinese han population. Int. J. Psychiatry Med. 2013, 46, 145-152. [CrossRef] [PubMed]

39. Zhang, X.; Yin, Y.; Liu, S.; Ma, X. A case-control association study between obsessive-compulsive disorder (OCD) and the MCP-1-2518G/A polymorphism in a chinese sample. Rev. Bras. Psiquiatr. 2012, 34, 451-453. [CrossRef] [PubMed]

40. Liu, S.; Liu, Y.; Zhang, X.; Ma, X. Lack of association of -251T/A polymorphism in interleukin 8 gene with susceptibility to obsessive-compulsive disorder in Chinese Han population. Cytokine 2012, 59, 209-210. [CrossRef] [PubMed]

41. Carpenter, L.L.; Heninger, G.R.; McDougle, C.J.; Tyrka, A.R.; Epperson, C.N.; Price, L.H. Cerebrospinal fluid interleukin-6 in obsessive-compulsive disorder and trichotillomania. Psychiatry Res. 2002, 112, 257-262. [CrossRef] 
42. Akdis, M.; Aab, A.; Altunbulakli, C.; Azkur, K.; Costa, R.A.; Crameri, R.; Duan, S.; Eiwegger, T.; Eljaszewicz, A.; Ferstl, R.; et al. Interleukins (from IL-1 to IL-38), interferons, transforming growth factor beta, and TNF-alpha: Receptors, functions, and roles in diseases. J. Allergy Clin. Immunol. 2016, 138, 984-1010. [CrossRef] [PubMed]

43. Yuce, M.; Guner, S.N.; Karabekiroglu, K.; Baykal, S.; Kilic, M.; Sancak, R.; Karabekiroglu, A. Association of tourette syndrome and obsessive-compulsive disorder with allergic diseases in children and adolescents: A preliminary study. Eur. Rev. Med. Pharmacol. Sci. 2014, 18, 303-310. [PubMed]

44. Stellwagen, D.; Malenka, R.C. Synaptic scaling mediated by glial tnf-alpha. Nature 2006, 440, 1054-1059. [CrossRef] [PubMed]

45. Beattie, E.C.; Stellwagen, D.; Morishita, W.; Bresnahan, J.C.; Ha, B.K.; Von Zastrow, M.; Beattie, M.S.; Malenka, R.C. Control of synaptic strength by glial tnfalpha. Science 2002, 295, 2282-2285. [CrossRef] [PubMed]

46. Krabbe, G.; Minami, S.S.; Etchegaray, J.I.; Taneja, P.; Djukic, B.; Davalos, D.; Le, D.; Lo, I.; Zhan, L.; Reichert, M.C.; et al. Microglial nfkappab-tnfalpha hyperactivation induces obsessive-compulsive behavior in mouse models of progranulin-deficient frontotemporal dementia. Proc. Natl. Acad. Sci. USA 2017, 114, 5029-5034. [CrossRef] [PubMed]

47. Gruol, D.L. Il-6 regulation of synaptic function in the cns. Neuropharmacology 2015, 96, 42-54. [CrossRef] [PubMed]

48. Bhattacharyya, S.; Khanna, S.; Chakrabarty, K.; Mahadevan, A.; Christopher, R.; Shankar, S.K. Anti-brain autoantibodies and altered excitatory neurotransmitters in obsessive-compulsive disorder. Neuropsychopharmacology 2009, 34, 2489-2496. [CrossRef] [PubMed]

49. Morer, A.; Lazaro, L.; Sabater, L.; Massana, J.; Castro, J.; Graus, F. Antineuronal antibodies in a group of children with obsessive-compulsive disorder and tourette syndrome. J. Psychiatr. Res. 2008, 42, 64-68. [CrossRef] [PubMed]

50. Dale, R.C.; Heyman, I.; Giovannoni, G.; Church, A.W. Incidence of anti-brain antibodies in children with obsessive-compulsive disorder. Br. J. Psychiatry 2005, 187, 314-319. [CrossRef] [PubMed]

51. Pearlman, D.M.; Vora, H.S.; Marquis, B.G.; Najjar, S.; Dudley, L.A. Anti-basal ganglia antibodies in primary obsessive-compulsive disorder: Systematic review and meta-analysis. Br. J. Psychiatry 2014, 205, 8-16. [CrossRef] [PubMed]

52. Akaltun, I.; Kara, S.S.; Kara, T. The relationship between Toxoplasma gondii IgG antibodies and generalized anxiety disorder and obsessive-compulsive disorder in children and adolescents: A new approach. Nord J. Psychiatry 2018, 72, 57-62. [CrossRef] [PubMed]

53. Mataix-Cols, D.; Frans, E.; Perez-Vigil, A.; Kuja-Halkola, R.; Gromark, C.; Isomura, K.; Fernandez de la Cruz, L.; Serlachius, E.; Leckman, J.F.; Crowley, J.J.; et al. A total-population multigenerational family clustering study of autoimmune diseases in obsessive-compulsive disorder and tourette's/chronic tic disorders. Mol. Psychiatry 2017. [CrossRef] [PubMed]

54. Flegr, J.; Horacek, J. Toxoplasma-infected subjects report an obsessive-compulsive disorder diagnosis more often and score higher in obsessive-compulsive inventory. Eur. Psychiatry 2017, 40, 82-87. [CrossRef] [PubMed]

55. Nicolini, H.; Lopez, Y.; Genis-Mendoza, A.D.; Manrique, V.; Lopez-Canovas, L.; Niubo, E.; Hernandez, L.; Bobes, M.A.; Riveron, A.M.; Lopez-Casamichana, M.; et al. Detection of anti-streptococcal, antienolase, and anti-neural antibodies in subjects with early-onset psychiatric disorders. Actas Esp. Psiquiatr. 2015, 43, 35-41. [PubMed]

56. Singer, H.S.; Mascaro-Blanco, A.; Alvarez, K.; Morris-Berry, C.; Kawikova, I.; Ben-Pazi, H.; Thompson, C.B.; Ali, S.F.; Kaplan, E.L.; Cunningham, M.W. Neuronal antibody biomarkers for sydenham's chorea identify a new group of children with chronic recurrent episodic acute exacerbations of tic and obsessive compulsive symptoms following a streptococcal infection. PLoS ONE 2015, 10, e0120499. [CrossRef] [PubMed]

57. Frankovich, J.; Thienemann, M.; Pearlstein, J.; Crable, A.; Brown, K.; Chang, K. Multidisciplinary clinic dedicated to treating youth with pediatric acute-onset neuropsychiatric syndrome: Presenting characteristics of the first 47 consecutive patients. J. Child Adolesc. Psychopharmacol. 2015, 25, 38-47. [CrossRef] [PubMed]

58. Cox, C.J.; Zuccolo, A.J.; Edwards, E.V.; Mascaro-Blanco, A.; Alvarez, K.; Stoner, J.; Chang, K.; Cunningham, M.W. Antineuronal antibodies in a heterogeneous group of youth and young adults with tics and obsessive-compulsive disorder. J. Child Adolesc. Psychopharmacol. 2015, 25, 76-85. [CrossRef] [PubMed] 
59. Ebrahimi Taj, F.; Noorbakhsh, S.; Ghavidel Darestani, S.; Shirazi, E.; Javadinia, S. Group a beta-hemolytic streptococcal infection in children and the resultant neuro-psychiatric disorder; A cross sectional study; Tehran, iran. Basic Clin. Neurosci. 2015, 6, 38-43. [PubMed]

60. Murphy, T.K.; Patel, P.D.; McGuire, J.F.; Kennel, A.; Mutch, P.J.; Parker-Athill, E.C.; Hanks, C.E.; Lewin, A.B.; Storch, E.A.; Toufexis, M.D.; et al. Characterization of the pediatric acute-onset neuropsychiatric syndrome phenotype. J. Child Adolesc. Psychopharmacol. 2015, 25, 14-25. [CrossRef] [PubMed]

61. Murphy, T.K.; Storch, E.A.; Lewin, A.B.; Edge, P.J.; Goodman, W.K. Clinical factors associated with pediatric autoimmune neuropsychiatric disorders associated with streptococcal infections. J. Pediatr. 2012, 160, 314-319. [CrossRef] [PubMed]

62. Leckman, J.F.; King, R.A.; Gilbert, D.L.; Coffey, B.J.; Singer, H.S.; Dure, L.S.T.; Grantz, H.; Katsovich, L.; Lin, H.; Lombroso, P.J.; et al. Streptococcal upper respiratory tract infections and exacerbations of tic and obsessive-compulsive symptoms: A prospective longitudinal study. J. Am. Acad. Child Adolesc. Psychiatry 2011, 50, 108-118.e3. [CrossRef] [PubMed]

63. Miman, O.; Mutlu, E.A.; Ozcan, O.; Atambay, M.; Karlidag, R.; Unal, S. Is there any role of Toxoplasma gondii in the etiology of obsessive-compulsive disorder? Psychiatry Res. 2010, 177, 263-265. [CrossRef] [PubMed]

64. Gause, C.; Morris, C.; Vernekar, S.; Pardo-Villamizar, C.; Grados, M.A.; Singer, H.S. Antineuronal antibodies in OCD: Comparisons in children with OCD-only, OCD+Chronic tics and OCD+PANDAS. J. Neuroimmunol. 2009, 214, 118-124. [CrossRef] [PubMed]

65. Kirvan, C.A.; Swedo, S.E.; Snider, L.A.; Cunningham, M.W. Antibody-mediated neuronal cell signaling in behavior and movement disorders. J. Neuroimmunol. 2006, 179, 173-179. [CrossRef] [PubMed]

66. Morer, A.; Vinas, O.; Lazaro, L.; Calvo, R.; Andres, S.; Bosch, J.; Gasto, C.; Massana, J.; Castro, J. Subtyping obsessive-compulsive disorder: Clinical and immunological findings in child and adult onset. J. Psychiatr. Res. 2006, 40, 207-213. [CrossRef] [PubMed]

67. Singer, H.S.; Hong, J.J.; Yoon, D.Y.; Williams, P.N. Serum autoantibodies do not differentiate PANDAS and tourette syndrome from controls. Neurology 2005, 65, 1701-1707. [CrossRef] [PubMed]

68. Pavone, P.; Bianchini, R.; Parano, E.; Incorpora, G.; Rizzo, R.; Mazzone, L.; Trifiletti, R.R. Anti-brain antibodies in PANDAS versus uncomplicated streptococcal infection. Pediatr. Neurol. 2004, 30, 107-110. [CrossRef]

69. Murphy, T.K.; Sajid, M.; Soto, O.; Shapira, N.; Edge, P.; Yang, M.; Lewis, M.H.; Goodman, W.K. Detecting pediatric autoimmune neuropsychiatric disorders associated with streptococcus in children with obsessive-compulsive disorder and tics. Biol. Psychiatry 2004, 55, 61-68. [CrossRef]

70. Luo, F.; Leckman, J.F.; Katsovich, L.; Findley, D.; Grantz, H.; Tucker, D.M.; Lombroso, P.J.; King, R.A.; Bessen, D.E. Prospective longitudinal study of children with tic disorders and/or obsessive-compulsive disorder: Relationship of symptom exacerbations to newly acquired streptococcal infections. Pediatrics 2004, 113, e578-e585. [CrossRef] [PubMed]

71. Inoff-Germain, G.; Rodriguez, R.S.; Torres-Alcantara, S.; Diaz-Jimenez, M.J.; Swedo, S.E.; Rapoport, J.L. An immunological marker (D8/17) associated with rheumatic fever as a predictor of childhood psychiatric disorders in a community sample. J. Child Psychol. Psychiatry 2003, 44, 782-790. [CrossRef] [PubMed]

72. Murphy, M.L.; Pichichero, M.E. Prospective identification and treatment of children with pediatric autoimmune neuropsychiatric disorder associated with group a streptococcal infection (PANDAS). Arch. Pediatr. Adolesc. Med. 2002, 156, 356-361. [CrossRef] [PubMed]

73. Eisen, J.L.; Leonard, H.L.; Swedo, S.E.; Price, L.H.; Zabriskie, J.B.; Chiang, S.Y.; Karitani, M.; Rasmussen, S.A. The use of antibody D8/17 to identify b cells in adults with obsessive-compulsive disorder. Psychiatry Res. 2001, 104, 221-225. [CrossRef]

74. Murphy, T.K.; Benson, N.; Zaytoun, A.; Yang, M.; Braylan, R.; Ayoub, E.; Goodman, W.K. Progress toward analysis of D8/17 binding to $\mathrm{b}$ cells in children with obsessive compulsive disorder and/or chronic tic disorder. J. Neuroimmunol. 2001, 120, 146-151. [CrossRef]

75. Peterson, B.S.; Leckman, J.F.; Tucker, D.; Scahill, L.; Staib, L.; Zhang, H.; King, R.; Cohen, D.J.; Gore, J.C.; Lombroso, P. Preliminary findings of antistreptococcal antibody titers and basal ganglia volumes in tic, obsessive-compulsive, and attention deficit/hyperactivity disorders. Arch. Gen. Psychiatry 2000, 57, 364-372. [CrossRef] [PubMed]

76. Marazziti, D.; Presta, S.; Pfanner, C.; Gemignani, A.; Rossi, A.; Sbrana, S.; Rocchi, V.; Ambrogi, F.; Cassano, G.B. Immunological alterations in adult obsessive-compulsive disorder. Biol. Psychiatry 1999, 46, 810-814. [CrossRef] 
77. Chapman, F.; Visvanathan, K.; Carreno-Manjarrez, R.; Zabriskie, J.B. A flow cytometric assay for d8/17 b cell marker in patients with tourette's syndrome and obsessive compulsive disorder. J. Immunol. Methods 1998, 219, 181-186. [CrossRef]

78. Khanna, S.; Ravi, V.; Shenoy, P.K.; Chandramukhi, A.; Channabasavanna, S.M. Viral antibodies in blood in obsessive compulsive disorder. Indian J. Psychiatry 1997, 39, 190-195. [PubMed]

79. Khanna, S.; Ravi, V.; Shenoy, P.K.; Chandramuki, A.; Channabasavanna, S.M. Cerebrospinal fluid viral antibodies in obsessive-compulsive disorder in an indian population. Biol. Psychiatry 1997, 41, 883-890. [CrossRef]

80. Murphy, T.K.; Goodman, W.K.; Fudge, M.W.; Williams, R.C., Jr.; Ayoub, E.M.; Dalal, M.; Lewis, M.H.; Zabriskie, J.B. B lymphocyte antigen D8/17: A peripheral marker for childhood-onset obsessive-compulsive disorder and tourette's syndrome? Am. J. Psychiatry 1997, 154, 402-407. [PubMed]

81. Swedo, S.E.; Leonard, H.L.; Mittleman, B.B.; Allen, A.J.; Rapoport, J.L.; Dow, S.P.; Kanter, M.E.; Chapman, F.; Zabriskie, J. Identification of children with pediatric autoimmune neuropsychiatric disorders associated with streptococcal infections by a marker associated with rheumatic fever. Am. J. Psychiatry 1997, 154, 110-112. [PubMed]

82. Zabriskie, J.B.; Lavenchy, D.; Williams, R.C., Jr.; Fu, S.M.; Yeadon, C.A.; Fotino, M.; Braun, D.G. Rheumatic fever-associated B cell alloantigens as identified by monoclonal antibodies. Arthritis Rheum. 1985, 28, 1047-1051. [CrossRef] [PubMed]

83. Patarroyo, M.E.; Winchester, R.J.; Vejerano, A.; Gibofsky, A.; Chalem, F.; Zabriskie, J.B.; Kunkel, H.G. Association of a B-cell alloantigen with susceptibility to rheumatic fever. Nature 1979, 278, 173-174. [CrossRef] [PubMed]

84. Morer, A.; Vinas, O.; Lazaro, L.; Bosch, J.; Toro, J.; Castro, J. D8/17 monoclonal antibody: An unclear neuropsychiatric marker. Behav. Neurol. 2005, 16, 1-8. [CrossRef] [PubMed]

85. Atmaca, M.; Kilic, F.; Koseoglu, F.; Ustundag, B. Neutrophils are decreased in obsessive-compulsive disorder: Preliminary investigation. Psychiatry Investig. 2011, 8, 362-365. [CrossRef] [PubMed]

86. Barber, Y.; Toren, P.; Achiron, A.; Noy, S.; Wolmer, L.; Weizman, R.; Laor, N. T cell subsets in obsessive-compulsive disorder. Neuropsychobiology 1996, 34, 63-66. [CrossRef] [PubMed]

87. Denys, D.; Fluitman, S.; Kavelaars, A.; Heijnen, C.; Westenberg, H.G. Effects of paroxetine and venlafaxine on immune parameters in patients with obsessive compulsive disorder. Psychoneuroendocrinology 2006, 31, 355-360. [CrossRef] [PubMed]

88. Marazziti, D.; Mungai, F.; Masala, I.; Baroni, S.; Vivarelli, L.; Ambrogi, F.; Catena Dell'Osso, M.; Consoli, G.; Massimetti, G.; Dell'Osso, L. Normalisation of immune cell imbalance after pharmacological treatments of patients suffering from obsessive-compulsive disorder. J. Psychopharmacol. 2009, 23, 567-573. [CrossRef] [PubMed]

89. Marazziti, D.; Baroni, S.; Masala, I.; Giannaccini, G.; Mungai, F.; Di Nasso, E.; Cassano, G.B. Decreased lymphocyte 3h-paroxetine binding in obsessive-compulsive disorder. Neuropsychobiology 2003, 47, 128-130. [CrossRef] [PubMed]

90. Marazziti, D.; Ori, M.; Nardini, M.; Rossi, A.; Nardi, I.; Cassano, G.B. Mrna expression of serotonin receptors of type $2 \mathrm{c}$ and $5 \mathrm{a}$ in human resting lymphocytes. Neuropsychobiology 2001, 43, 123-126. [CrossRef] [PubMed]

91. Rocca, P.; Beoni, A.M.; Eva, C.; Ferrero, P.; Maina, G.; Bogetto, F.; Ravizza, L. Lymphocyte peripheral benzodiazepine receptor mrna decreases in obsessive-compulsive disorder. Eur. Neuropsychopharmacol. 2000, 10, 337-340. [CrossRef]

92. Ravindran, A.V.; Griffiths, J.; Merali, Z.; Anisman, H. Circulating lymphocyte subsets in obsessive compulsive disorder, major depression and normal controls. J. Affect. Disords 1999, 52, 1-10. [CrossRef]

93. Rocca, P.; Ferrero, P.; Gualerzi, A.; Zanalda, E.; Maina, G.; Bergamasco, B.; Ravizza, L. Peripheral-type benzodiazepine receptors in anxiety disorders. Acta Psychiatr. Scand. 1991, 84, 537-544. [CrossRef] [PubMed]

94. Ursoiu, F.; Moleriu, L.; Lungeanu, D.; Puschita, M. The association between hiv clinical disease severity and psychiatric disorders as seen in western romania. AIDS Care 2018. [CrossRef] [PubMed]

95. Dale, R.C.; Heyman, I.; Surtees, R.A.; Church, A.J.; Giovannoni, G.; Goodman, R.; Neville, B.G. Dyskinesias and associated psychiatric disorders following streptococcal infections. Arch. Dis. Child. 2004, 89, 604-610. [CrossRef] [PubMed] 
96. Giulino, L.; Gammon, P.; Sullivan, K.; Franklin, M.; Foa, E.; Maid, R.; March, J.S. Is parental report of upper respiratory infection at the onset of obsessive-compulsive disorder suggestive of pediatric autoimmune neuropsychiatric disorder associated with streptococcal infection? J. Child Adolesc. Psychopharmacol. 2002, 12, 157-164. [CrossRef] [PubMed]

97. Lougee, L.; Perlmutter, S.J.; Nicolson, R.; Garvey, M.A.; Swedo, S.E. Psychiatric disorders in first-degree relatives of children with pediatric autoimmune neuropsychiatric disorders associated with streptococcal infections (PANDAS). J. Am. Acad. Child Adolesc. Psychiatry 2000, 39, 1120-1126. [CrossRef] [PubMed]

98. Johnco, C.; Kugler, B.B.; Murphy, T.K.; Storch, E.A. Obsessive-compulsive symptoms in adults with lyme disease. Gen. Hosp. Psychiatry 2018, 51, 85-89. [CrossRef] [PubMed]

99. Stagi, S.; Lepri, G.; Rigante, D.; Matucci Cerinic, M.; Falcini, F. Cross-sectional evaluation of plasma vitamin $\mathrm{d}$ levels in a large cohort of italian patients with pediatric autoimmune neuropsychiatric disorders associated with streptococcal infections. J. Child Adolesc. Psychopharmacol. 2018, 28, 124-129. [CrossRef] [PubMed]

100. Calaprice, D.; Tona, J.; Parker-Athill, E.C.; Murphy, T.K. A survey of pediatric acute-onset neuropsychiatric syndrome characteristics and course. J. Child Adolesc. Psychopharmacol. 2017, 27, 607-618. [CrossRef] [PubMed]

101. Wang, H.C.; Lau, C.I.; Lin, C.C.; Chang, A.; Kao, C.H. Group a streptococcal infections are associated with increased risk of pediatric neuropsychiatric disorders: A taiwanese population-based cohort study. J. Clin. Psychiatry 2016, 77, e848-e854. [CrossRef] [PubMed]

102. Murphy, T.K.; Storch, E.A.; Turner, A.; Reid, J.M.; Tan, J.; Lewin, A.B. Maternal history of autoimmune disease in children presenting with tics and/or obsessive-compulsive disorder. J. Neuroimmunol. 2010, 229, 243-247. [CrossRef] [PubMed]

103. Kurlan, R.; Johnson, D.; Kaplan, E.L.; Tourette Syndrome Study Group. Streptococcal infection and exacerbations of childhood tics and obsessive-compulsive symptoms: A prospective blinded cohort study. Pediatrics 2008, 121, 1188-1197. [CrossRef] [PubMed]

104. Giedd, J.N.; Rapoport, J.L.; Garvey, M.A.; Perlmutter, S.; Swedo, S.E. Mri assessment of children with obsessive-compulsive disorder or tics associated with streptococcal infection. Am. J. Psychiatry 2000, 157, 281-283. [CrossRef] [PubMed]

105. Swedo, S.E.; Leonard, H.L.; Garvey, M.; Mittleman, B.; Allen, A.J.; Perlmutter, S.; Lougee, L.; Dow, S.; Zamkoff, J.; Dubbert, B.K. Pediatric autoimmune neuropsychiatric disorders associated with streptococcal infections: Clinical description of the first 50 cases. Am. J. Psychiatry 1998, 155, 264-271. [CrossRef] [PubMed]

106. Streptococcus Pyogenes: Basic Biology to Clinical Manifestations; Ferretti, J.J.; Stevens, D.L.; Fischetti, V.A. (Eds.) University of Oklahoma Health Sciences Center: Oklahoma City, OK, USA, 2016.

107. Cunningham, M.W. Post-streptococcal autoimmune sequelae: Rheumatic fever and beyond. In Streptococcus Pyogenes: Basic Biology to Clinical Manifestations; Ferretti, J.J., Stevens, D.L., Fischetti, V.A., Eds.; University of Oklahoma Health Sciences Center: Oklahoma City, OK, USA, 2016.

108. Dajani, A.S. Guidelines for the diagnosis of rheumatic fever. Jones criteria, 1992 update. Special writing group of the committee on rheumatic fever, endocarditis, and kawasaki disease of the council on cardiovascular disease in the young of the american heart association. JAMA 1992, 268, 2069-2073.

109. Yanagawa, B.; Butany, J.; Verma, S. Update on rheumatic heart disease. Curr. Opin. Cardiol. 2016, 31, $162-168$. [CrossRef] [PubMed]

110. Macerollo, A.; Martino, D. Pediatric autoimmune neuropsychiatric disorders associated with streptococcal infections (PANDAS): An evolving concept. Tremor Other Hyperkinet. Mov. 2013, 3. [CrossRef]

111. Cunningham, M.W.; Cox, C.J. Autoimmunity against dopamine receptors in neuropsychiatric and movement disorders: A review of sydenham chorea and beyond. Acta Physiol. 2016, 216, 90-100. [CrossRef] [PubMed]

112. Park, J. Movement disorders following cerebrovascular lesion in the basal ganglia circuit. J. Mov. Disords 2016, 9, 71-79. [CrossRef] [PubMed]

113. Orefici, G.; Cardona, F.; Cox, C.J.; Cunningham, M.W. Pediatric autoimmune neuropsychiatric disorders associated with streptococcal infections (PANDAS). In Streptococcus Pyogenes: Basic Biology to Clinical Manifestations; Ferretti, J.J., Stevens, D.L., Fischetti, V.A., Eds.; University of Oklahoma Health Sciences Center: Oklahoma City, OK, USA, 2016. 
114. Cox, C.J.; Sharma, M.; Leckman, J.F.; Zuccolo, J.; Zuccolo, A.; Kovoor, A.; Swedo, S.E.; Cunningham, M.W. Brain human monoclonal autoantibody from sydenham chorea targets dopaminergic neurons in transgenic mice and signals dopamine d2 receptor: Implications in human disease. J. Immunol. 2013, 191, 5524-5541. [CrossRef] [PubMed]

115. Fibbe, L.A.; Cath, D.C.; van den Heuvel, O.A.; Veltman, D.J.; Tijssen, M.A.; van Balkom, A.J. Relationship between movement disorders and obsessive-compulsive disorder: Beyond the obsessive-compulsive-tic phenotype. A systematic review. J. Neurol. Neurosurg. Psychiatry 2012, 83, 646-654. [CrossRef] [PubMed]

116. Frick, L.R.; Rapanelli, M.; Jindachomthong, K.; Grant, P.; Leckman, J.F.; Swedo, S.; Williams, K.; Pittenger, C. Differential binding of antibodies in PANDAS patients to cholinergic interneurons in the striatum. Brain. Behav. Immun. 2018, 69, 304-311. [CrossRef] [PubMed]

117. Jaspers-Fayer, F.; Han, S.H.J.; Chan, E.; McKenney, K.; Simpson, A.; Boyle, A.; Ellwyn, R.; Stewart, S.E. Prevalence of acute-onset subtypes in pediatric obsessive-compulsive disorder. J. Child Adolesc. Psychopharmacol. 2017, 27, 332-341. [CrossRef] [PubMed]

118. Leon, J.; Hommer, R.; Grant, P.; Farmer, C.; D'Souza, P.; Kessler, R.; Williams, K.; Leckman, J.F.; Swedo, S. Longitudinal outcomes of children with pediatric autoimmune neuropsychiatric disorder associated with streptococcal infections (PANDAS). Eur. Child Adolesc. Psychiatry 2018, 27, 637-643. [CrossRef] [PubMed]

119. Skoog, G.; Skoog, I. A 40-year follow-up of patients with obsessive-compulsive disorder. Arch. Gen. Psychiatry 1999, 56, 121-127. [CrossRef] [PubMed]

120. Calaprice, D.; Tona, J.; Murphy, T.K. Treatment of pediatric acute-onset neuropsychiatric disorder in a large survey population. J. Child Adolesc. Psychopharmacol. 2018, 28, 92-103. [CrossRef] [PubMed]

121. Brown, K.; Farmer, C.; Farhadian, B.; Hernandez, J.; Thienemann, M.; Frankovich, J. Pediatric acute-onset neuropsychiatric syndrome response to oral corticosteroid bursts: An observational study of patients in an academic community-based PANS clinic. J. Child Adolesc. Psychopharmacol. 2017, 27, 629-639. [CrossRef] [PubMed]

122. Spartz, E.J.; Freeman, G.M., Jr.; Brown, K.; Farhadian, B.; Thienemann, M.; Frankovich, J. Course of neuropsychiatric symptoms after introduction and removal of nonsteroidal anti-inflammatory drugs: A pediatric observational study. J. Child Adolesc. Psychopharmacol. 2017, 27, 652-659. [CrossRef] [PubMed]

123. Murphy, T.K.; Brennan, E.M.; Johnco, C.; Parker-Athill, E.C.; Miladinovic, B.; Storch, E.A.; Lewin, A.B. A double-blind randomized placebo-controlled pilot study of azithromycin in youth with acute-onset obsessive-compulsive disorder. J. Child Adolesc. Psychopharmacol. 2017, 27, 640-651. [CrossRef] [PubMed]

124. Williams, K.A.; Swedo, S.E.; Farmer, C.A.; Grantz, H.; Grant, P.J.; D’Souza, P.; Hommer, R.; Katsovich, L.; King, R.A.; Leckman, J.F. Randomized, controlled trial of intravenous immunoglobulin for pediatric autoimmune neuropsychiatric disorders associated with streptococcal infections. J. Am. Acad. Child Adolesc. Psychiatry 2016, 55, 860-867.e2. [CrossRef] [PubMed]

125. Sigra, S.; Hesselmark, E.; Bejerot, S. Treatment of PANDAS and PANS: A systematic review. Neurosci. Biobehav. Rev. 2018, 86, 51-65. [CrossRef] [PubMed]

126. Brown, K.D.; Farmer, C.; Freeman, G.M., Jr.; Spartz, E.J.; Farhadian, B.; Thienemann, M.; Frankovich, J. Effect of early and prophylactic nonsteroidal anti-inflammatory drugs on flare duration in pediatric acute-onset neuropsychiatric syndrome: An observational study of patients followed by an academic community-based pediatric acute-onset neuropsychiatric syndrome clinic. J. Child Adolesc. Psychopharmacol. 2017, 27, 619-628. [PubMed]

127. Nadeau, J.M.; Jordan, C.; Selles, R.R.; Wu, M.S.; King, M.A.; Patel, P.D.; Hanks, C.E.; Arnold, E.B.; Lewin, A.B.; Murphy, T.K.; et al. A pilot trial of cognitive-behavioral therapy augmentation of antibiotic treatment in youth with pediatric acute-onset neuropsychiatric syndrome-related obsessive-compulsive disorder. J. Child Adolesc. Psychopharmacol. 2015, 25, 337-343. [CrossRef] [PubMed]

128. Latimer, M.E.; L'Etoile, N.; Seidlitz, J.; Swedo, S.E. Therapeutic plasma apheresis as a treatment for 35 severely ill children and adolescents with pediatric autoimmune neuropsychiatric disorders associated with streptococcal infections. J. Child Adolesc. Psychopharmacol. 2015, 25, 70-75. [CrossRef] [PubMed]

129. Demesh, D.; Virbalas, J.M.; Bent, J.P. The role of tonsillectomy in the treatment of pediatric autoimmune neuropsychiatric disorders associated with streptococcal infections (PANDAS). JAMA Otolaryngol. Head Neck Surg. 2015, 141, 272-275. [CrossRef] [PubMed] 
130. Pavone, P.; Rapisarda, V.; Serra, A.; Nicita, F.; Spalice, A.; Parano, E.; Rizzo, R.; Maiolino, L.; Di Mauro, P.; Vitaliti, G.; et al. Pediatric autoimmune neuropsychiatric disorder associated with group a streptococcal infection: The role of surgical treatment. Int. J. Immunopathol. Pharmacol 2014, 27, 371-378. [CrossRef] [PubMed]

131. Bernstein, G.A.; Victor, A.M.; Pipal, A.J.; Williams, K.A. Comparison of clinical characteristics of pediatric autoimmune neuropsychiatric disorders associated with streptococcal infections and childhood obsessive-compulsive disorder. J. Child Adolesc. Psychopharmacol. 2010, 20, 333-340. [CrossRef] [PubMed]

132. Storch, E.A.; Murphy, T.K.; Geffken, G.R.; Mann, G.; Adkins, J.; Merlo, L.J.; Duke, D.; Munson, M.; Swaine, Z.; Goodman, W.K. Cognitive-behavioral therapy for PANDAS-related obsessive-compulsive disorder: Findings from a preliminary waitlist controlled open trial. J. Am. Acad. Child Adolesc. Psychiatry 2006, 45, 1171-1178. [CrossRef] [PubMed]

133. Snider, L.A.; Lougee, L.; Slattery, M.; Grant, P.; Swedo, S.E. Antibiotic prophylaxis with azithromycin or penicillin for childhood-onset neuropsychiatric disorders. Biol. Psychiatry 2005, 57, 788-792. [CrossRef] [PubMed]

134. Garvey, M.A.; Perlmutter, S.J.; Allen, A.J.; Hamburger, S.; Lougee, L.; Leonard, H.L.; Witowski, M.E.; Dubbert, B.; Swedo, S.E. A pilot study of penicillin prophylaxis for neuropsychiatric exacerbations triggered by streptococcal infections. Biol. Psychiatry 1999, 45, 1564-1571. [CrossRef]

135. Shalbafan, M.; Mohammadinejad, P.; Shariat, S.V.; Alavi, K.; Zeinoddini, A.; Salehi, M.; Askari, N.; Akhondzadeh, S. Celecoxib as an adjuvant to fluvoxamine in moderate to severe obsessive-compulsive disorder: A double-blind, placebo-controlled, randomized trial. Pharmacopsychiatry 2015, 48, 136-140. [CrossRef] [PubMed]

136. Sayyah, M.; Boostani, H.; Pakseresht, S.; Malayeri, A. A preliminary randomized double-blind clinical trial on the efficacy of celecoxib as an adjunct in the treatment of obsessive-compulsive disorder. Psychiatry Res. 2011, 189, 403-406. [CrossRef] [PubMed]

137. Esalatmanesh, S.; Abrishami, Z.; Zeinoddini, A.; Rahiminejad, F.; Sadeghi, M.; Najarzadegan, M.R.; Shalbafan, M.R.; Akhondzadeh, S. Minocycline combination therapy with fluvoxamine in moderate-to-severe obsessive-compulsive disorder: A placebo-controlled, double-blind, randomized trial. Psychiatry Clin. Neurosci. 2016, 70, 517-526. [CrossRef] [PubMed]

138. Rodriguez, C.I.; Bender, J., Jr.; Marcus, S.M.; Snape, M.; Rynn, M.; Simpson, H.B. Minocycline augmentation of pharmacotherapy in obsessive-compulsive disorder: An open-label trial. J. Clin. Psychiatry 2010, 71, 1247-1249. [CrossRef] [PubMed]

139. Ghanizadeh, A.; Mohammadi, M.R.; Bahraini, S.; Keshavarzi, Z.; Firoozabadi, A.; Alavi Shoshtari, A. Efficacy of $\mathrm{N}$-acetylcysteine augmentation on obsessive compulsive disorder: A multicenter randomized double blind placebo controlled clinical trial. Iran. J. Psychiatry 2017, 12, 134-141. [PubMed]

140. Costa, D.L.C.; Diniz, J.B.; Requena, G.; Joaquim, M.A.; Pittenger, C.; Bloch, M.H.; Miguel, E.C.; Shavitt, R.G. Randomized, double-blind, placebo-controlled trial of $\mathrm{N}$-acetylcysteine augmentation for treatment-resistant obsessive-compulsive disorder. J. Clin. Psychiatry 2017, 78, e766-e773. [CrossRef] [PubMed]

141. Paydary, K.; Akamaloo, A.; Ahmadipour, A.; Pishgar, F.; Emamzadehfard, S.; Akhondzadeh, S. $\mathrm{N}$-acetylcysteine augmentation therapy for moderate-to-severe obsessive-compulsive disorder: Randomized, double-blind, placebo-controlled trial. J. Clin. Pharm. Ther. 2016, 41, 214-219. [CrossRef] [PubMed]

142. Sarris, J.; Oliver, G.; Camfield, D.A.; Dean, O.M.; Dowling, N.; Smith, D.J.; Murphy, J.; Menon, R.; Berk, M.; Blair-West, S.; et al. N-acetyl cysteine (NAC) in the treatment of obsessive-compulsive disorder: A 16-week, double-blind, randomised, placebo-controlled study. CNS Drugs 2015, 29, 801-809. [CrossRef] [PubMed]

143. Afshar, H.; Roohafza, H.; Mohammad-Beigi, H.; Haghighi, M.; Jahangard, L.; Shokouh, P.; Sadeghi, M.; Hafezian, H. N-acetylcysteine add-on treatment in refractory obsessive-compulsive disorder: A randomized, double-blind, placebo-controlled trial. J Clin. Psychopharmacol. 2012, 32, 797-803. [CrossRef] [PubMed]

144. Hamdani, N.; Daban-Huard, C.; Lajnef, M.; Richard, J.R.; Delavest, M.; Godin, O.; Le Guen, E.; Vederine, F.E.; Lepine, J.P.; Jamain, S.; et al. Relationship between Toxoplasma gondii infection and bipolar disorder in a french sample. J. Affect. Disord 2013, 148, 444-448. [CrossRef] [PubMed]

145. Fond, G.; Capdevielle, D.; Macgregor, A.; Attal, J.; Larue, A.; Brittner, M.; Ducasse, D.; Boulenger, J.P. Toxoplasma gondii: A potential role in the genesis of psychiatric disorders. Encephale 2013, 39, 38-43. [CrossRef] [PubMed] 
146. Strittmatter, C.; Lang, W.; Wiestler, O.D.; Kleihues, P. The changing pattern of human immunodeficiency virus-associated cerebral toxoplasmosis: A study of 46 postmortem cases. Acta Neuropathol. 1992, 83, 475-481. [CrossRef] [PubMed]

147. Ueno, N.; Lodoen, M.B. From the blood to the brain: Avenues of eukaryotic pathogen dissemination to the central nervous system. Curr. Opin. Microbiol. 2015, 26, 53-59. [CrossRef] [PubMed]

148. Courret, N.; Darche, S.; Sonigo, P.; Milon, G.; Buzoni-Gatel, D.; Tardieux, I. CD11c- and CD11b-expressing mouse leukocytes transport single Toxoplasma gondii tachyzoites to the brain. Blood 2006, 107, 309-316. [CrossRef] [PubMed]

149. Dellacasa-Lindberg, I.; Fuks, J.M.; Arrighi, R.B.; Lambert, H.; Wallin, R.P.; Chambers, B.J.; Barragan, A. Migratory activation of primary cortical microglia upon infection with Toxoplasma gondii. Infect. Immun. 2011, 79, 3046-3052. [CrossRef] [PubMed]

150. Notarangelo, F.M.; Wilson, E.H.; Horning, K.J.; Thomas, M.A.; Harris, T.H.; Fang, Q.; Hunter, C.A.; Schwarcz, R. Evaluation of kynurenine pathway metabolism in Toxoplasma gondii-infected mice: Implications for schizophrenia. Schizophr. Res. 2014, 152, 261-267. [CrossRef] [PubMed]

151. Mosienko, V.; Beis, D.; Pasqualetti, M.; Waider, J.; Matthes, S.; Qadri, F.; Bader, M.; Alenina, N. Life without brain serotonin: Reevaluation of serotonin function with mice deficient in brain serotonin synthesis. Behav. Brain Res. 2015, 277, 78-88. [CrossRef] [PubMed]

152. Mandi, Y.; Vecsei, L. The kynurenine system and immunoregulation. J. Neural. Transm. 2012, 119, 197-209. [CrossRef] [PubMed]

153. Yadav, M.C.; Burudi, E.M.; Alirezaei, M.; Flynn, C.C.; Watry, D.D.; Lanigan, C.M.; Fox, H.S. IFN-gamma-induced ido and wrs expression in microglia is differentially regulated by IL-4. Glia 2007, 55, 1385-1396. [CrossRef] [PubMed]

154. Guillemin, G.J.; Smythe, G.; Takikawa, O.; Brew, B.J. Expression of indoleamine 2,3-dioxygenase and production of quinolinic acid by human microglia, astrocytes, and neurons. Glia 2005, 49, 15-23. [CrossRef] [PubMed]

155. Daubener, W.; MacKenzie, C.R. IFN-gamma activated indoleamine 2,3-dioxygenase activity in human cells is an antiparasitic and an antibacterial effector mechanism. Adv. Exp. Med. Biol. 1999, 467, 517-524. [PubMed]

156. Booij, L.; Van der Does, W.; Benkelfat, C.; Bremner, J.D.; Cowen, P.J.; Fava, M.; Gillin, C.; Leyton, M.; Moore, P.; Smith, K.A.; et al. Predictors of mood response to acute tryptophan depletion: A reanalysis. Neuropsychopharmacology 2002, 27, 852-861. [CrossRef]

157. Romanelli, R.J.; Wu, F.M.; Gamba, R.; Mojtabai, R.; Segal, J.B. Behavioral therapy and serotonin reuptake inhibitor pharmacotherapy in the treatment of obsessive-compulsive disorder: A systematic review and meta-analysis of head-to-head randomized controlled trials. Depress. Anxiety 2014, 31, 641-652. [CrossRef] [PubMed]

158. Yatham, L.N.; Liddle, P.F.; Sossi, V.; Erez, J.; Vafai, N.; Lam, R.W.; Blinder, S. Positron emission tomography study of the effects of tryptophan depletion on brain serotonin(2) receptors in subjects recently remitted from major depression. Arch. Gen. Psychiatry 2012, 69, 601-609. [CrossRef] [PubMed]

159. Hughes, M.M.; Carballedo, A.; McLoughlin, D.M.; Amico, F.; Harkin, A.; Frodl, T.; Connor, T.J. Tryptophan depletion in depressed patients occurs independent of kynurenine pathway activation. Brain Behav. Immun. 2012, 26, 979-987. [CrossRef] [PubMed]

160. Prandovszky, E.; Gaskell, E.; Martin, H.; Dubey, J.P.; Webster, J.P.; McConkey, G.A. The neurotropic parasite Toxoplasma gondii increases dopamine metabolism. PLoS ONE 2011, 6, e23866. [CrossRef] [PubMed]

161. Soares-Cunha, C.; Coimbra, B.; Sousa, N.; Rodrigues, A.J. Reappraising striatal D1- and D2-neurons in reward and aversion. Neurosci. Biobehav. Rev. 2016, 68, 370-386. [CrossRef] [PubMed]

162. Wichers, M.C.; Koek, G.H.; Robaeys, G.; Verkerk, R.; Scharpe, S.; Maes, M. Ido and interferon-alpha-induced depressive symptoms: A shift in hypothesis from tryptophan depletion to neurotoxicity. Mol. Psychiatry 2005, 10, 538-544. [CrossRef] [PubMed]

163. Prendergast, G.C.; Malachowski, W.J.; Mondal, A.; Scherle, P.; Muller, A.J. Indoleamine 2,3-dioxygenase and its therapeutic inhibition in cancer. Int. Rev. Cell Mol. Biol. 2018, 336, 175-203. [PubMed]

164. Reus, G.Z.; Becker, I.R.T.; Scaini, G.; Petronilho, F.; Oses, J.P.; Kaddurah-Daouk, R.; Ceretta, L.B.; Zugno, A.I.; Dal-Pizzol, F.; Quevedo, J.; et al. The inhibition of the kynurenine pathway prevents behavioral disturbances and oxidative stress in the brain of adult rats subjected to an animal model of schizophrenia. Prog. Neuropsychopharmacol. Biol. Psychiatry 2018, 81, 55-63. [CrossRef] [PubMed] 
165. Fineberg, N.A.; Reghunandanan, S.; Simpson, H.B.; Phillips, K.A.; Richter, M.A.; Matthews, K.; Stein, D.J.; Sareen, J.; Brown, A.; Sookman, D.; et al. Obsessive-compulsive disorder (OCD): Practical strategies for pharmacological and somatic treatment in adults. Psychiatry Res. 2015, 227, 114-125. [CrossRef] [PubMed]

166. Perlmutter, S.J.; Leitman, S.F.; Garvey, M.A.; Hamburger, S.; Feldman, E.; Leonard, H.L.; Swedo, S.E. Therapeutic plasma exchange and intravenous immunoglobulin for obsessive-compulsive disorder and tic disorders in childhood. Lancet 1999, 354, 1153-1158. [CrossRef]

167. Cooperstock, M.S.; Swedo, S.E.; Pasternack, M.S.; Murphy, T.K.; PANS/PANDAS Consortium. Clinical management of pediatric acute-onset neuropsychiatric syndrome: Part III-Treatment and prevention of infections. J. Child Adolesc. Psychopharmacol. 2017, 27, 594-606. [CrossRef]

168. National Institute of Mental Health (NIMH). Information about PANS/PANDAS. Available online: https: / / www.nimh.nih.gov/labs-at-nimh/research-areas/clinics-and-labs/sbp/information-aboutpans-pandas.shtml (accessed on 30 March 2018).

169. Frankovich, J.; Swedo, S.; Murphy, T.; Dale, R.C.; Agalliu, D.; Williams, K.; Daines, M.; Hornig, M.; Chugani, H.; Sanger, T.; et al. Clinical Management of pediatric acute-onset neuropsychiatric syndrome: Part II-Use of immunomodulatory therapies. J. Child Adolesc. Psychopharmacol. 2017, 27, 574-593. [CrossRef]

170. Kellner, M.; Nowack, S.; Wortmann, V.; Yassouridis, A.; Wiedemann, K. Does pregnenolone enhance exposure therapy in obsessive-compulsive disorder?-A pilot, interim report of a randomized, placebo-controlled, double-blind study. Pharmacopsychiatry 2016, 49, 79-81. [CrossRef] [PubMed]

171. Murphy, T.K.; Parker-Athill, E.C.; Lewin, A.B.; Storch, E.A.; Mutch, P.J. Cefdinir for recent-onset pediatric neuropsychiatric disorders: A pilot randomized trial. J. Child Adolesc. Psychopharmacol. 2015, 25, 57-64. [CrossRef] [PubMed]

172. Kalueff, A.V.; Stewart, A.M.; Song, C.; Berridge, K.C.; Graybiel, A.M.; Fentress, J.C. Neurobiology of rodent self-grooming and its value for translational neuroscience. Nat. Rev. Neurosci. 2016, 17, 45-59. [CrossRef] [PubMed]

173. Welch, J.M.; Lu, J.; Rodriguiz, R.M.; Trotta, N.C.; Peca, J.; Ding, J.D.; Feliciano, C.; Chen, M.; Adams, J.P.; Luo, J.; et al. Cortico-striatal synaptic defects and OCD-like behaviours in Sapap3-mutant mice. Nature 2007, 448, 894-900. [CrossRef] [PubMed]

174. Gehring, W.J.; Hiromi, Y. Homeotic genes and the homeobox. Annu. Rev. Genet. 1986, 20, 147-173. [CrossRef] [PubMed]

175. Chen, S.K.; Tvrdik, P.; Peden, E.; Cho, S.; Wu, S.; Spangrude, G.; Capecchi, M.R. Hematopoietic origin of pathological grooming in Hoxb8 mutant mice. Cell 2010, 141, 775-785. [CrossRef] [PubMed]

176. Brimberg, L.; Benhar, I.; Mascaro-Blanco, A.; Alvarez, K.; Lotan, D.; Winter, C.; Klein, J.; Moses, A.E.; Somnier, F.E.; Leckman, J.F.; et al. Behavioral, pharmacological, and immunological abnormalities after streptococcal exposure: A novel rat model of sydenham chorea and related neuropsychiatric disorders. Neuropsychopharmacology 2012, 37, 2076-2087. [CrossRef] [PubMed]

177. Lotan, D.; Cunningham, M.; Joel, D. Antibiotic treatment attenuates behavioral and neurochemical changes induced by exposure of rats to group a streptococcal antigen. PLoS ONE 2014, 9, e101257. [CrossRef] [PubMed]

178. Pauls, D.L.; Raymond, C.L.; Stevenson, J.M.; Leckman, J.F. A family study of gilles de la tourette syndrome. Am. J. Hum. Genet. 1991, 48, 154-163. [PubMed]

179. Eapen, V.; Pauls, D.L.; Robertson, M.M. Evidence for autosomal dominant transmission in tourette's syndrome. United kingdom cohort study. Br. J. Psychiatry 1993, 162, 593-596. [CrossRef] [PubMed]

180. Kataoka, Y.; Kalanithi, P.S.; Grantz, H.; Schwartz, M.L.; Saper, C.; Leckman, J.F.; Vaccarino, F.M. Decreased number of parvalbumin and cholinergic interneurons in the striatum of individuals with tourette syndrome. J. Comp. Neurol. 2010, 518, 277-291. [CrossRef] [PubMed]

181. Frick, L.R.; Williams, K.; Pittenger, C. Microglial dysregulation in psychiatric disease. Clin. Dev. Immunol. 2013, 2013, 608654. [CrossRef] [PubMed]

182. Morer, A.; Chae, W.; Henegariu, O.; Bothwell, A.L.; Leckman, J.F.; Kawikova, I. Elevated expression of MCP-1, IL-2 and PTPR-N in basal ganglia of tourette syndrome cases. Brain Behav. Immun. 2010, 24, 1069-1073. [CrossRef] [PubMed]

183. Bilbo, S.D.; Schwarz, J.M. The immune system and developmental programming of brain and behavior. Front. Neuroendocrinol. 2012, 33, 267-286. [CrossRef] [PubMed] 
184. Attwells, S.; Setiawan, E.; Wilson, A.A.; Rusjan, P.M.; Mizrahi, R.; Miler, L.; Xu, C.; Richter, M.A.; Kahn, A.; Kish, S.J.; et al. Inflammation in the neurocircuitry of obsessive-compulsive disorder. JAMA Psychiatry 2017, 74, 833-840. [CrossRef] [PubMed]

185. Scott, G.; Zetterberg, H.; Jolly, A.; Cole, J.H.; De Simoni, S.; Jenkins, P.O.; Feeney, C.; Owen, D.R.; Lingford-Hughes, A.; Howes, O.; et al. Minocycline reduces chronic microglial activation after brain trauma but increases neurodegeneration. Brain 2018, 141, 459-471. [CrossRef] [PubMed]

186. Fernandez, T.V.; Leckman, J.F.; Pittenger, C. Genetic susceptibility in obsessive-compulsive disorder. Handb. Clin. Neurol. 2018, 148, 767-781. [PubMed]

187. Pishva, E.; Drukker, M.; Viechtbauer, W.; Decoster, J.; Collip, D.; van Winkel, R.; Wichers, M.; Jacobs, N.; Thiery, E.; Derom, C.; et al. Epigenetic genes and emotional reactivity to daily life events: A multi-step gene-environment interaction study. PLoS ONE 2014, 9, e100935. [CrossRef] [PubMed]

188. Carlsson, E.; Frostell, A.; Ludvigsson, J.; Faresjo, M. Psychological stress in children may alter the immune response. J. Immunol. 2014, 192, 2071-2081. [CrossRef] [PubMed]

189. Leboyer, M.; Oliveira, J.; Tamouza, R.; Groc, L. Is it time for immunopsychiatry in psychotic disorders? Psychopharmacology 2016, 233, 1651-1660. [CrossRef] [PubMed]

190. Leboyer, M.; Berk, M.; Yolken, R.H.; Tamouza, R.; Kupfer, D.; Groc, L. Immuno-psychiatry: An agenda for clinical practice and innovative research. BMC Med. 2016, 14, 173. [CrossRef] [PubMed]

(c) 2018 by the authors. Licensee MDPI, Basel, Switzerland. This article is an open access article distributed under the terms and conditions of the Creative Commons Attribution (CC BY) license (http://creativecommons.org/licenses/by/4.0/). 